\title{
Direct versus conventional anticoagulants for treatment of cancer associated thrombosis: a pooled and interaction analysis between observational studies and randomized clinical trials
}

\author{
Zhi-Chun Gu ${ }^{1,2 \#}$, Yi-Dan Yan ${ }^{1 \#}$, Sheng-Yan Yang ${ }^{3 \#}$, Long Shen ${ }^{2}$, Ling-Cong Kong ${ }^{2}$, Chi Zhang ${ }^{1}$, \\ An-Hua Wei ${ }^{3,4}$, Zheng Li ${ }^{2}$, Xin-Hua Wang ${ }^{2}$, Hou-Wen Lin ${ }^{1}$ \\ ${ }^{1}$ Department of Pharmacy, ${ }^{2}$ Department of Cardiology, Renji Hospital, School of Medicine, Shanghai Jiaotong University, Shanghai 200127, China; \\ ${ }^{3}$ Department of Pharmacy, Changzheng Hospital, Second Military Medical University, Shanghai 200003, China; ${ }^{4}$ Department of Pharmacy, Tongji \\ Hospital, Tongji Medical College, Huazhong University of Science and Technology, Wuhan 430030, China \\ Contributions: (I) Conception and design: ZC Gu, YD Yan; (II) Administrative support: XH Wang, Zheng L; (III) Provision of study materials or \\ patients: L Shen, LC Kong, C Zhang, AH Wei; (IV) Collection and assembly of data: ZC Gu, YD Yan, SY Yang; (V) Data analysis and interpretation: \\ ZC Gu, YD Yan, SY Yang; (VI) Manuscript writing: All authors; (VII) Final approval of manuscript: All authors. \\ \#These authors contributed equally to this work. \\ Correspondence to: Zheng Li, MD, PhD; Xin-Hua Wang, MD, PhD. Department of Cardiology, Renji Hospital, School of Medicine, Shanghai \\ Jiaotong University, Shanghai 200127, China. Email: schoenlz@126.com; ttwwxh@126.com.
}

Background: There are emerging observational studies (OSs) to assess real-world comparative effectiveness and safety of direct oral anticoagulants (DOACs) in cancer associated thrombosis (CAT). We conducted a pooled and interaction analysis to compare the treatment effect estimates of DOACs between OSs and randomized controlled trials (RCTs).

Methods: We systematically searched PUBMED, EMBASE and Cochrane Library for OSs and RCTs that reported recurrent venous thromboembolism (VTE) and/or major bleeding events in CAT patients receiving DOACs and conventional anticoagulants [warfarin or low molecular-weight heparins (LMWHs)]. Relative risks (RRs) for OSs and RCTs were calculated using random-effects models separately, and interaction analyses were afterward applied to assess the comparability between OSs and RCTs.

Results: Baseline characteristic was comparable between identified 10 OSs (35,142 patients) and 8 RCTs (2,602 patients). Overall, no significant difference of treatment effect estimates between OSs and RCTs was detected ( $\mathrm{P}_{\text {interaction }}$ : 0.42 for recurrent VTE; $\mathrm{P}_{\text {interaction }}$ : 0.38 for major bleeding). DOACs significantly decreased the risk of recurrent VTE compared with conventional anticoagulants in CAT patients (RR: 0.74, 95\% CI: 0.63-0.86, I²: 0\% for OSs; RR: 0.65, 95\% CI: 0.49-0.86; I²: 0\% for RCTs), without increasing major bleeding risk (RR: 0.90, 95\% CI: 0.76-1.07, I'2: $24.0 \%$ for OSs; RR: $1.17,95 \%$ CI: $0.72-1.88, I^{2}$ : $26.2 \%$ for RCTs). Whereas, increased risk of gastrointestinal bleeding (GIB) was found with DOACs versus conventional anticoagulants in CAT patients (RR: 2.77, 95\% CI: 1.35-5.68, I²: 0\% for RCTs). Analyses of subgroups, based on comparators and follow-up duration, did not significantly affect results.

Conclusions: In this study, effectiveness and safety of DOACs versus conventional anticoagulants in CAT from OSs are in agreement with those from RCTs, confirming a low risk of recurrent VTE and similar risk of major bleeding in CAT patients receiving DOACs.

Keywords: Cancer associated thrombosis (CAT); direct oral anticoagulants (DOACs); recurrent venous thromboembolism (VTE); major bleeding; observational study (OS)

Submitted Sep 30, 2019. Accepted for publication Nov 21, 2019.

doi: 10.21037/atm.2019.12.152

View this article at: http://dx.doi.org/10.21037/atm.2019.12.152 


\section{Introduction}

Patients with cancer, due to their pathological hypercoagulability, have a 4 to 7 -fold increased risk of venous thromboembolism (VTE) relative to those without cancer (1). Among malignancy, VTE patients were 3 times more likely to be hospitalized, with an additional 7 hospital days and around 24\% decreased 1-year survival rate compared to those without VTE (2,3). Anticoagulation regimen is the cornerstone for the management of cancerassociated thrombosis (CAT), yet its use is challenging in these fragile patients due to a delicate balance between high risk of recurrent VTE and bleeding (4). Current practice guidelines are unanimous in their recommendation of low molecular-weight heparins (LMWHs) as first-line treatment for CAT. The landmark CLOT trial reveals that $\mathrm{LMWH}$ is more effective than vitamin-K antagonists (VKAs) in reducing recurrent VTE risk, without increasing major bleeding risk (5). However, in the real-world practice, LMWH use is burdensome as the requirement of daily subcutaneous injections, which inevitably limits its longterm adoption (6). Of late, direct oral anticoagulants (DOACs) represent a convenient and effective alternative to VKAs for the prevention of stroke in atrial fibrillation and the prophylaxis or treatment in VTE $(7,8)$. Whereas, clinical trials of DOACs that specially aimed at patients with cancer remain scarce. Previous several meta-analyses have addressed this issue but were limited by inclusion of only post-hoc analysis from Randomized controlled trials (RCTs), thereby leading to an insufficient sample size estimation for the reduction in recurrent VTE from 3\% to 5\% (9-15). Publication of several pivotal RCTs, such as Hokusai VTE Cancer and SELECT-D, fueled systematical reassessment of DOACs treatment in CAT patients $(16,17)$.

RCTs and their meta-analyses certainly represent the highest quality of evidence and are the basis for guidelines by healthcare organizations (18). However, RCTs are often conduced on specific populations or in specialized scenarios that differ from real clinical settings, yielding high internal validity (i.e., reliable relative treatment effect estimates) but low external validity (i.e., generalizability to real-world practice) (18). Observational studies (OSs) have traditionally been considered methodologically weaker than RCTs (19). However, there is increased awareness that OSs support and extend RCT findings to large patient populations in realworld clinical practice and, as such, are complementary to RCTs. Therefore, the evidence derived from OSs and their meta-analyses may facilitate validation of conclusions drawn from RCTs and reassure decision-makers that findings can be extrapolated to real-world populations. This study therefore assesses the effectiveness and safety of DOACs in CAT between OSs and RCTs.

\section{Methods}

\section{Literature search and study selection}

This systematic review was reported in line with a prespecified protocol (PROSPERO: CRD42019132607, https://www.crd.york.ac.uk/PROSPERO/display_record. php? RecordID =132607) and standards in PRISMA Statement and Cochrane Collaboration (20,21). Databases of PUBMED, EMBASE, and Cochrane Library was systematically searched from inception to May 15, 2019, with the language restriction of English, to identify potentially eligible OSs and RCTs comparing DOACs with conventional anticoagulants (LMWH or VKAs) in CAT and reporting data on recurrent VTE and major bleeding. Full details of search strategy were presented in Table S1. Any potential studies from bibliographies of pertinent articles were also identified. As for OSs, when several studies used the same data source from an overlapping period, the one that reported interested data with the longest study period was included. Studies that published only in conference abstract or letter form were excluded. Two reviewers (ZC Gu, YD Yan) independently assessed the study titles and abstracts to determine eligibility, and full articles were thereafter retrieved and assessed according to inclusion criteria, with any disagreements being resolved by corresponding authors ( $\mathrm{Z} \mathrm{Li}, \mathrm{XH}$ Wang).

\section{Study outcomes, data extraction, and quality evaluation}

The primary outcomes of this study were recurrent VTE and major bleeding, and the secondary outcome was clinical related non-major bleeding (CRNMB), according to International Society on Thrombosis and Hemostasis (ISTH) criteria (22). A prespecified form was used to extract data with the following items: study characteristics, patient demographics and clinical characteristics, data on recurrent VTE, major bleeding and CRNMB. The methodological quality of included RCTs was evaluated according to Cochrane Collaboration Risk of Bias Tool (23). Because OSs have a higher risk of bias than RCTs, several important factors in design and methods have been considered to mitigate bias when comparing study outcomes between 
DOAC and comparator in OS (24). Low, moderate, or high risk of bias was allocated to each citation within the following items: (I) use of adjusted method to deal with selection bias; (II) potential for residual confounding; (III) use of methods to handle time-varying covariates and information censoring, and (IV) reporting detailed baseline characteristics and outcome measures.

\section{Data analysis}

Forest plots were used to measure the primary and secondary outcomes for included OSs and RCTs. Relative risks (RRs) and their 95\% CI were calculated using random-effects models. Statistical heterogeneity was assessed using $\mathrm{I}^{2}$ test, and a value of $>50 \%$ represented considerable heterogeneity (25). Subgroup analyses were thereafter conducted on the basis of individual DOACs (rivaroxaban, dabigatran, apixaban, edoxaban), bleeding types (fatal, intracranial, gastrointestinal, urogenital bleeding), comparison (VKAs and LMWH), and follow-up duration ( $\leq 6$ and $>6$ months). Finally, interaction analyses were used to assess the comparability between OSs and RCTs. In addition, to test the robustness of primary results, series sensitivity analyses were performed by sequential eliminating each study from the pool, merging OSs and RCTs simultaneously, or using adjusted effective size as the measurement. Afterward, interaction analyses were also used to compare the difference between result of sensitivity analyses and result of primacy analyses. Publication bias was evaluated by visual funnel plots and quantitative Egger's test if available (21). All the Statistics were performed employing STATA software (version13, Statacorp, College Station, Texas, USA), and a $P$ value of $<0.05$ indicated a statistically significant difference.

\section{Results}

\section{Search results and study evaluation}

The initial search yielded 1,754 records, among them 1,720 records were excluded by screening titles and abstracts. The remaining 34 full-text articles were reviewed and 16 articles were excluded for reasons listed in Figure 1 and Table S2. Finally, a total of 18 studies involving 37,744 CAT patients met the inclusion criteria $(16,17,26-41) ; 10$ were OSs ( 5 for rivaroxaban and 5 for DOACs) and 8 were RCTs (3 for rivaroxaban; 2 for dabigatran; 2 for edoxaban; and 1 for apixaban); 35,142 patients $(8,855$ with DOACs and
26,287 with conventional anticoagulants) in OSs and 2,602 patients (1,338 with DOACs and 1,264 with conventional anticoagulants) in RCTs were included. Table 1 showed the characteristics of OSs. All of included OSs were conducted in the USA and follow-up duration wildly ranged from 3 to 12 months. The characteristics of RCTs were outlined in Table 2. The publication period ranged from 2010 to 2018, with the up-to-date Hokusai VTE Cancer and SELECT-D trials published in 2018. Detailed patients and clinical characteristics were summarized in Tables S3,S4. As shown in Table 3, baseline characteristic was comparable between included OSs and RCTs ( $\mathrm{P}>0.05$ for each characteristic). No high-risk bias tool items were detected in OSs (Table 4). The included RCTs satisfied all bias tool items except for 4 open-label trials (Table 5). Thus, the included studies were of modest to high quality.

\section{Comparison of recurrent VTE and bleeding risk between OSs and RCTs}

The incidence of recurrent VTE was $12.3 \%(613 / 4,990)$ after pooling 10 OSs data: $10.8 \%(252 / 2,339)$ in DOACs group and $13.6 \%(361 / 2,651)$ in conventional anticoagulants group, indicating a lower risk of recurrent VTE in patients allocated to DOACs than those assigned to conventional anticoagulants (RR: 0.74, 95\% CI: 0.63-0.86, $\left.\mathrm{I}^{2}: 0 \%\right)$. Similarly, decreased risk of VTE recurrence was found in RCTs (RR: 0.65 , 95\% CI: $0.49-0.86$; $\mathrm{I}^{2}: 0 \%$ ). No significant difference for recurrent VTE was observed between OSs and RCTs ( $\mathrm{P}_{\text {interaction: }}$ 0.42) (Figures 2A,S1,S2). As for individual DOACs, rivaroxaban (RR: 0.73, 95\% CI: 0.63-0.86, I': $0 \%$ for OSs; RR: 0.51, 95\% CI: 0.27-0.97, $I^{2}: 0 \%$ for RCTs; $\left.P_{\text {interaction: }}: 0.24\right)$ and edoxaban (RR: 0.68, 95\% CI: $0.47-0.98, \mathrm{I}^{2}: 0 \%$ for RCTs) conferred a lower risk of recurrent VTE in CAT patients (Figures 2A,S3,S4). Regarding major bleeding risk, 35,142 patients from 10 OSs were included, amongst them $4.4 \%(393 / 8,855)$ of DOACs users and $4.8 \%(1,266 / 26,287)$ of conventional anticoagulants users experienced major bleeding, with a similar risk between DOACs and conventional anticoagulants (RR: $0.90,95 \%$ CI: $0.76-1.07, \mathrm{I}^{2}: 24.0 \%$ ). The result of RCTs was in line with that from OSs (RR: 1.17, 95\% CI: $\left.0.72-1.88, \mathrm{I}^{2}: 26.2 \%\right)$. The difference for major bleeding between OSs and RCTs was not significant $\left(\mathrm{P}_{\text {interaction: }}: 0.38\right)$ (Figures $\left.2 B, S 5, S 6\right)$. With regards to individual DOACs, rivaroxaban appeared at similar risk of major bleeding (RR: $1.18,95 \%$ CI: $0.92-1.52, I^{2}$ : $0 \%$ for OSs; RR: $0.98,95 \%$ CI: $0.27-3.53, \mathrm{I}^{2}: 67.2 \%$ for RCTs; 


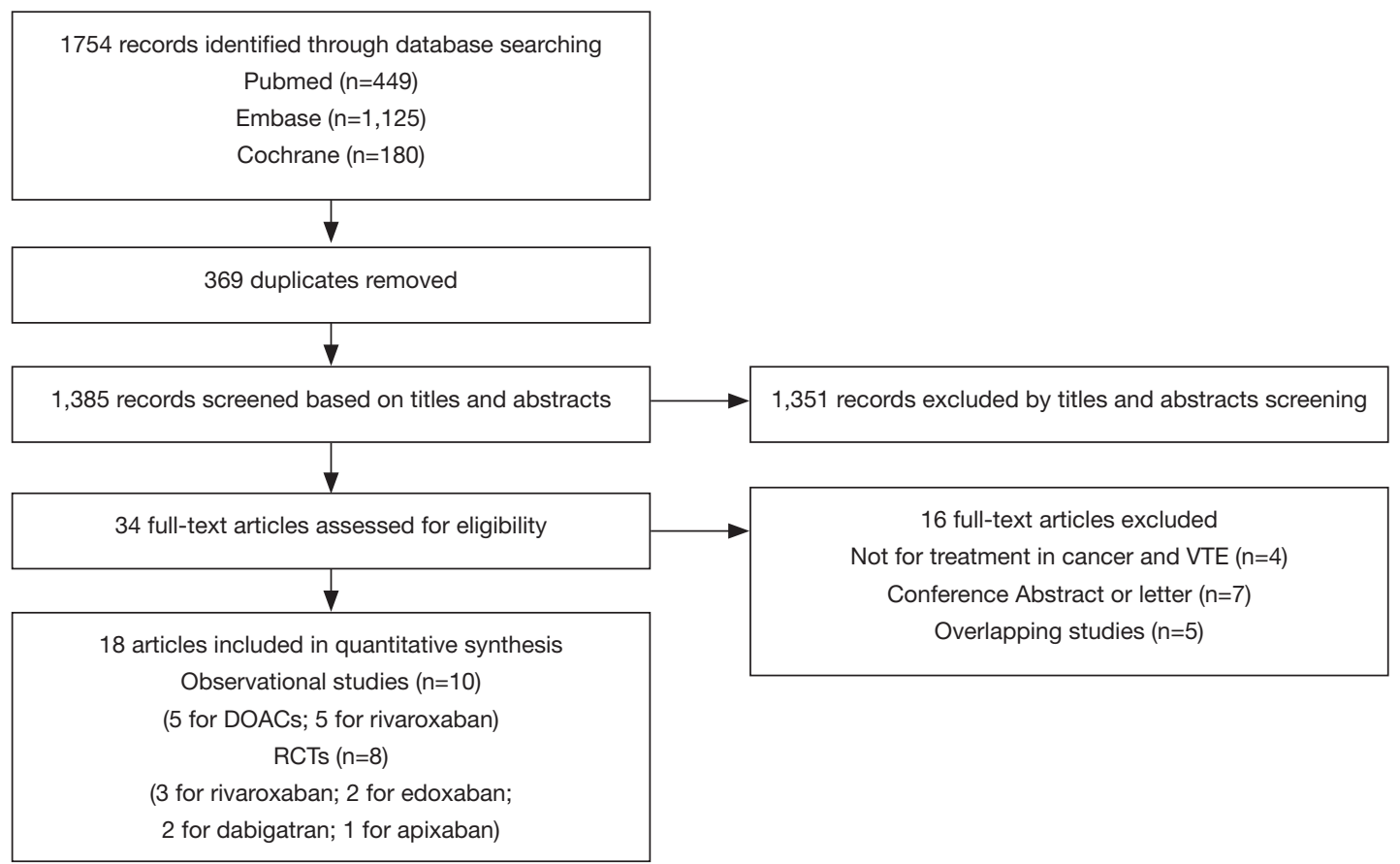

Figure 1 Flow diagram for the selection of eligible studies. VTE, venous thromboembolism; DOACs, direct oral anticoagulants; RCTs, randomized controlled trials.

Table 1 Characteristics of included observational studies

\begin{tabular}{|c|c|c|c|c|c|c|}
\hline Study (Indication) & $\begin{array}{l}\text { Country or region/data source/inclusion } \\
\text { period }\end{array}$ & $\begin{array}{l}\text { Interventions/ } \\
\text { Numbers }\end{array}$ & Controls/Numbers & $\begin{array}{c}\text { Adjusted } \\
\text { method }\end{array}$ & $\begin{array}{l}\text { Follow-up } \\
\text { (months) }\end{array}$ & $\begin{array}{l}\text { Outcome } \\
\text { ascertainment }\end{array}$ \\
\hline Alzghari 2018 & $\begin{array}{l}\text { USA/Scott \& White Medical } \\
\text { Center/2013.6-2015.9 }\end{array}$ & DOACs/48 & $\begin{array}{l}\text { Wafarin/56, } \\
\text { LMWH/23 }\end{array}$ & NR & 10 & NR \\
\hline Chaudhury 2018 & $\begin{array}{l}\text { USA/H. Lee Moffitt Cancer } \\
\text { Center/2010.1-2015.6 }\end{array}$ & Rivaroxaban/107 & LWMH/179 & NR & 6 & NR \\
\hline Ross 2017 & $\begin{array}{l}\text { USA/The University of Texas MD Anderson } \\
\text { Cancer Center/2014-2015 }\end{array}$ & DOACs/30 & LWMH/123 & NR & 11.6 & ICD-9 \\
\hline Signorelli 2017 & $\begin{array}{l}\text { USA/Augusta University Medical } \\
\text { Center/2013.7-2015.6 }\end{array}$ & Rivaroxaban/18 & $\begin{array}{l}\text { Wafarin/5, } \\
\text { LMWH/26 }\end{array}$ & NR & 6 & NR \\
\hline Nicklaus 2018 & $\begin{array}{l}\text { USA/University of Missouri Health } \\
\text { Care/2012.1-2015.8 }\end{array}$ & Rivaroxaban/45 & LWMH/45 & NR & 3 & NR \\
\hline Phelps 2019 & $\begin{array}{l}\text { USA/The Arthur G. James Cancer } \\
\text { Hospital/2010.12-2016.1 }\end{array}$ & DOACs/190 & LWMH/290 & NR & 6 & NR \\
\hline Zakai 2018 & $\begin{array}{l}\text { USA/Truven Health MarketScan Commercial } \\
\text { Claims and Encounters Database and the } \\
\text { Medicare Supplemental and Coordination of } \\
\text { Benefits Database/2011.1-2015.9 }\end{array}$ & DOACs/3,258 & $\begin{array}{l}\text { Wafarin/14833, } \\
\mathrm{LMWH} / 8803\end{array}$ & HDPS & 7 & ICD-9 \\
\hline Pritchard 2019 & $\begin{array}{l}\text { USA/Academic institution with a cancer } \\
\text { center/2012.1-2015.10 }\end{array}$ & DOACs/80 & $\begin{array}{l}\text { Wafarin/83, } \\
\mathrm{LMWH} / 95\end{array}$ & NR & 12 & ICD-9 \\
\hline
\end{tabular}

IPTW, inverse probability of treatment weighting; HDPS, high dimensional propensity scores; ICD, international classification of diseases; LWMH, low molecular weight heparin; NR, not reported; DOACs, direct oral anticoagulants; VTE, venous thromboembolism. 
Table 2 Characteristics of included RCTs

\begin{tabular}{|c|c|c|c|c|c|c|c|}
\hline Study & Indication & NCT & Interventions & Numbers & Controls & Numbers & $\begin{array}{l}\text { Follow-up } \\
\text { (months) }\end{array}$ \\
\hline SELECT-D & Cancer and VTE & NCT02583191 & $\begin{array}{l}\text { Rivaroxaban } 15 \mathrm{mg} \\
\text { twice and then } 20 \mathrm{mg} \\
\text { once }\end{array}$ & 203 & $\begin{array}{l}\text { Dalteparin } 200 \text { IU per } \\
\text { kilogram }\end{array}$ & 203 & 6 \\
\hline $\begin{array}{l}\text { Hokusai VTE } \\
\text { Cancer }\end{array}$ & Cancer and VTE & NCT02073682 & Edoxaban $60 \mathrm{mg}$ once & 522 & $\begin{array}{l}\text { Dalteparin } 200 \text { IU per } \\
\text { kilogram }\end{array}$ & 524 & 12 \\
\hline EINSTEIN-PE/DVT & Cancer and VTE & $\begin{array}{l}\text { NCT00440193/ } \\
\text { NCT00439777 }\end{array}$ & $\begin{array}{l}\text { Rivaroxaban } 15 \mathrm{mg} \\
\text { twice and then } 20 \mathrm{mg} \\
\text { once }\end{array}$ & 258 & $\begin{array}{l}\text { Enoxaparin } 1.0 \mathrm{mg} \text { per } \\
\text { kilogram and VKA }\end{array}$ & 204 & 12 \\
\hline
\end{tabular}

RCTs, randomized controlled trials; VTE, venous thromboembolism.

Table 3 Baseline characteristic of observational studies and included RCTs

\begin{tabular}{lccc}
\hline Baseline characteristic & $\begin{array}{c}\text { OSs } \\
(\mathrm{N}=35,142)\end{array}$ & $\begin{array}{c}\mathrm{RCTs} \\
(\mathrm{N}=2,602)\end{array}$ & $\mathrm{P}$ \\
\hline Mean age (y) & 63.5 & 64.9 & 0.36 \\
Female (\%) & 51.5 & 46.6 & 0.49 \\
BMI (kg/m²) & 28.2 & 27.0 & 0.06 \\
Metastatic cancer (\%) & 54.7 & 43.1 & 0.10 \\
Hematologic cancer (\%) & 13.6 & 10.1 & 0.44 \\
Gastric cancer (\%) & 9.0 & 6.5 & 0.51 \\
Pancreas cancer (\%) & 6.2 & 3.8 & 0.44 \\
Lung cancer (\%) & 14.6 & 11.2 & 0.47 \\
Lymphoma (\%) & 6.3 & 5.0 & 0.69 \\
Gynecologic cancer (\%) & 7.3 & 8.9 & 0.68 \\
Bladder cancer (\%) & 3.9 & 3.9 & 1.00 \\
Brain cancer (\%) & 3.4 & 1.3 & 0.33 \\
\hline
\end{tabular}

$\mathrm{P}$ was conducted by t-test for continuous variable and chisquare test for dichotomy variable. BMI, body mass index; RCT, randomized controlled trial; OS, observational study.
$\left.\mathrm{P}_{\text {interaction }}: 0.80\right)$, whereas edoxaban might associated with an increased risk of major bleeding (RR: $1.69,95 \% \mathrm{CI}$ : 1.04-2.77, I': 0\% for RCTs) (Figures 2B,S7,S8). Likewise, patients receiving DOACs carried a similar risk of CRNMB compared to those taking conventional anticoagulants (RR: 1.73, 95\% CI: $1.16-2.57, \mathrm{I}^{2}$ : $0 \%$ for OSs; RR: $1.17,95 \%$ CI: $0.76-1.78, \mathrm{I}^{2}: 66.9 \%$ for RCTs; $\mathrm{P}_{\text {interaction }}$ : 0.21 ) (Figure $2 B, S 9, S 10)$.

\section{Comparison of major bleeding types between OSs and RCTs}

Further analysis on the types of major bleeding were summarized in Figures 3,S11,S12. Data from OSs and RCTs showed a similar risk of fatal bleeding (RR: $3.33,95 \% \mathrm{CI}$ : 0.68-16.26 for OSs; RR: 0.20, 95\% CI: 0.01-4.17 for RCTs) as well as risk of urogenital bleeding (RR: $0.72,95 \% \mathrm{CI}$ : $0.37-1.39, \mathrm{I}^{2}: 0 \%$ for OSs; RR: $6.14,95 \%$ CI: $0.72-52.4, \mathrm{I}^{2}$ : $0 \%$ for RCTs) in patients with DOACs versus conventional anticoagulants. No significant difference of the treatment effect estimates was found between OSs and RCTs $\left(\mathrm{P}_{\text {interaction }}\right.$ : 0.45 for fatal bleeding; $\mathrm{P}_{\text {interaction }}$ : 0.68 for urogenital bleeding). Merged result from OSs showed that DOACs associated with reduced risk of intracranial bleeding 
Table 4 Quality assessment of observational studies

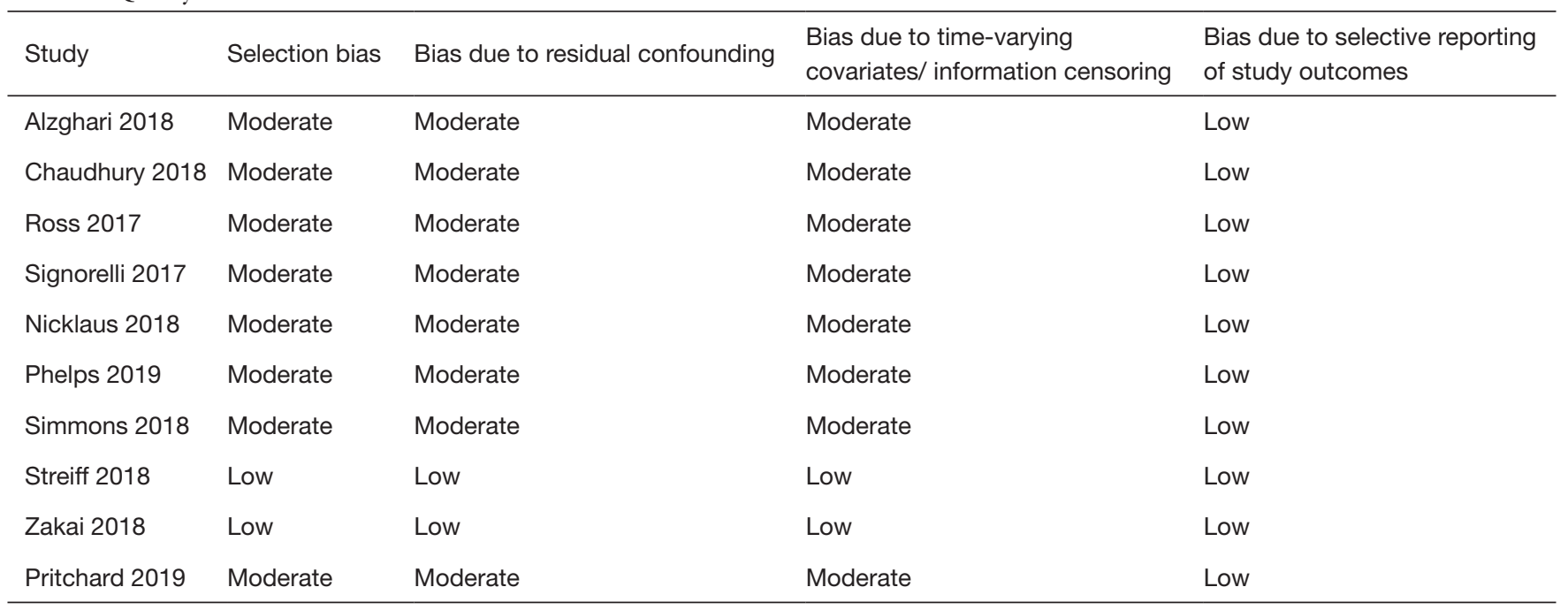

Low, low risk; Moderate, moderate risk, unclear risk; High, high risk

Table 5 Quality assessment of RCTs

\begin{tabular}{|c|c|c|c|c|c|c|c|}
\hline Study & $\begin{array}{l}\text { Random sequence } \\
\text { generation }\end{array}$ & $\begin{array}{l}\text { Allocation } \\
\text { concealment }\end{array}$ & $\begin{array}{l}\text { Blinding of participants } \\
\text { and personnel }\end{array}$ & $\begin{array}{l}\text { Blinding of outcome } \\
\text { assessment }\end{array}$ & $\begin{array}{l}\text { Incomplete } \\
\text { outcome data }\end{array}$ & $\begin{array}{l}\text { Selective } \\
\text { reporting }\end{array}$ & $\begin{array}{l}\text { Other } \\
\text { bias }\end{array}$ \\
\hline SELECT-D & Low & Low & High & Low & Low & Low & Low \\
\hline Hokusai VTE Cancer & Low & Unclear & High & Low & Low & Low & Low \\
\hline AMPLIFY & Low & Low & Low & Low & Low & Low & Low \\
\hline RECOVER-I/II & Low & Low & Low & Low & Low & Low & Low \\
\hline
\end{tabular}

$\mathrm{RCT}$, randomized controlled trial; Low, low risk; unclear, unclear risk; High, high risk.

(RR: $0.59,95 \%$ CI: $0.38-0.91, \mathrm{I}^{2}: 0 \%$ ). By contrast, after summing 2 RCTs, patients allocated to DOACs significantly increased the risk of major gastrointestinal bleeding (GIB) when compared to conventional anticoagulants (RR: 2.77, 95\% CI: $\left.1.35-5.68, \mathrm{I}^{2}: 0 \%\right)$.

\section{Recurrent VTE and major bleeding risk based on comparators and follow-up}

Similar with the primacy results, reduced risk of recurrent VTE was also observed in patients receiving DOACs versus warfarin (RR: $0.75,95 \%$ CI: $0.61-0.93, \mathrm{I}^{2}: 0 \%$ for OSs; RR: $0.66,95 \%$ CI: $0.39-1.11, I^{2}: 0 \%$ for RCTs; $\mathrm{P}_{\text {interaction: }}$ : 0.65 ) or versus LMWH (RR: $0.72,95 \%$ CI: $0.58-0.89$, $I^{2}: 0 \%$ for OSs; RR: $0.64,95 \%$ CI: $0.46-0.91, I^{2}: 0 \%$ for
RCTs; $\mathrm{P}_{\text {interaction }}$ : 0.57) (Figures $\left.4 A, S 13, S 14\right)$. Regarding major bleeding, 2 RCTs involving 1,452 patients were identified, and the incidence of major bleeding was $6.48 \%$ (47/725) in DOACs group compared to $3.71 \%(27 / 727)$ in LMWH group, indicating increased risk between DOACs and LMWH (RR: 1.75, 95\% CI: 1.10-2.77, I²: $0 \%)$. Nevertheless, compared with warfarin, data from OSs showed that DOACs were at decreased risk of major bleeding (RR: 0.79, 95\% CI: 0.67-0.92, I²: 0\%) (Figures $4 B, S 15, S 16)$. In terms of different follow-up duration, decreased risk of VTE recurrence of DOACs versus conventional anticoagulants was found in both short-term follow up (RR: $0.71,95 \%$ CI: $0.43-1.17, I^{2}$ : $0 \%$ for OSs; RR: $0.59,95 \%$ CI: $0.35-1.00, \mathrm{I}^{2}: 0 \%$ for RCTs; $\mathrm{P}_{\text {interaction }}$ : 0.63 ) and long-term follow up (RR: 0.70, 95\% CI: $0.42-$ 

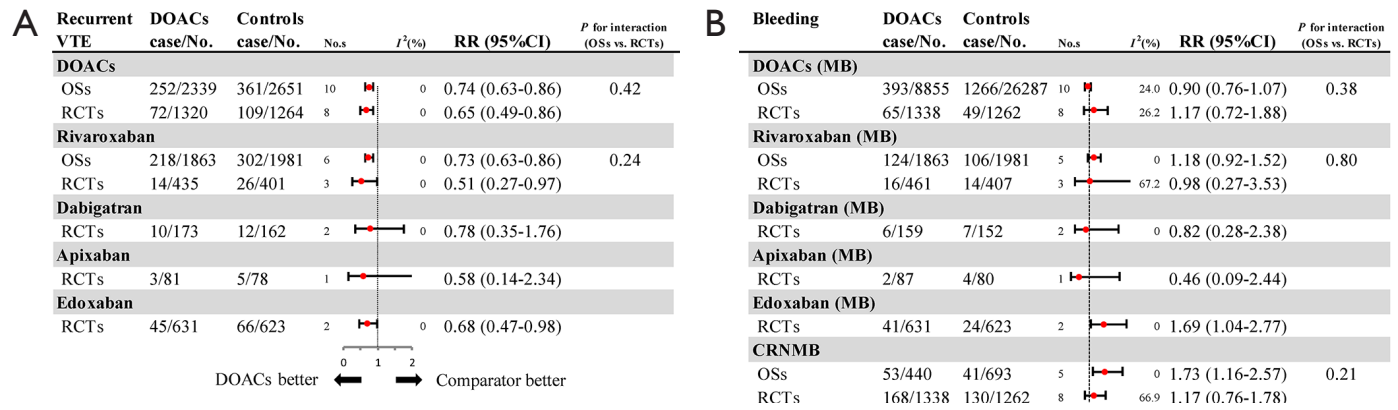

Figure 2 (A) Risk of recurrent VTE by DOACs and individuals and (B) risk of bleeding by DOACs and individuals. VTE, venous thromboembolism; DOACs, direct oral anticoagulants; RCTs, randomized controlled trials; OSs, observational studies; MB, major bleeding; CRNMB, clinical related non-major bleeding; RR, relative risk; No., number of included studies.

\begin{tabular}{|c|c|c|c|c|c|c|c|}
\hline $\begin{array}{l}\text { Major } \\
\text { bleeding }\end{array}$ & $\begin{array}{l}\text { DOACs } \\
\text { case/No. }\end{array}$ & $\begin{array}{l}\text { Controls } \\
\text { case/No. }\end{array}$ & No. & & $I^{2}(\%)$ & $\operatorname{RR}(95 \% \mathrm{CI})$ & $\begin{array}{l}P \text { for interaction } \\
\text { (OSs s. RCTs) } \\
\end{array}$ \\
\hline \multicolumn{8}{|l|}{ Overall } \\
\hline OSs & $393 / 8855$ & $1266 / 26287$ & 10 & $\eta$ & 24.0 & $0.90(0.76-1.07)$ & 0.38 \\
\hline RCTs & $65 / 1338$ & $49 / 1262$ & 8 & 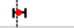 & 26.2 & $1.17(0.72-1.88)$ & \\
\hline \multicolumn{8}{|c|}{ Fatal bleeding } \\
\hline OSs & $6 / 160$ & $2 / 178$ & 1 & & & $3.33(0.68-16.26)$ & 0.45 \\
\hline RCTs & $0 / 522$ & $2 / 524$ & 1 & $\longrightarrow$ & & $0.20(0.01-4.17)$ & \\
\hline \multicolumn{8}{|c|}{ Intracranial bleeding } \\
\hline OSs & $25 / 8283$ & $136 / 25495$ & 4 & 4 & 0 & $0.59(0.38-0.91)$ & 0.90 \\
\hline RCTs & $2 / 522$ & $4 / 524$ & 1 & $\rightarrow$ & & $0.50(0.09-2.73)$ & \\
\hline \multicolumn{8}{|c|}{ Gastro intestinal bleeding } \\
\hline OSs & $225 / 8390$ & $740 / 25674$ & 5 & 1 & 58.5 & $1.05(0.76-1.44)$ & 0.12 \\
\hline RCTs & $28 / 725$ & $10 / 727$ & 2 & $\longmapsto$ & 0 & $2.77(1.35-5.68)$ & \\
\hline \multicolumn{8}{|c|}{ Urogenital bleeding } \\
\hline OSs & $15 / 1767$ & $23 / 1859$ & 3 & w & 0 & $0.72(0.37-1.39)$ & 0.68 \\
\hline RCTs & $6 / 725$ & 0/727 & 2 & & -0 & $6.14(0.72-52.4)$ & \\
\hline
\end{tabular}

Figure 3 Risk of major bleeding by types. RCTs, randomized controlled trials; OSs, observational studies; RR, relative risk; No., number of included studies.

$1.17, \mathrm{I}^{2}: 0 \%$ for OSs; RR: $0.67,95 \%$ CI: $0.48-0.95, \mathrm{I}^{2}: 0 \%$ for RCTs; $\left.\mathrm{P}_{\text {interaction: }}: 0.89\right)$. Also, no significant difference for major bleeding between OSs and RCTs was found in shortterm follow up subgroup $\left(\mathrm{P}_{\text {interaction }}\right.$ : 0.52$)$ and long-term follow up subgroup $\left(\mathrm{P}_{\text {interaction }}\right.$ : 0.67) (Figures 4,S17-S20).

\section{Sensitivity analysis and publication bias}

Sensitivity analyses failed to identify any individual trial as having influenced the primacy outcome (Tables S5,S6). Also, further analyses by pooling OSs and RCTs (VTE outcome: $\mathrm{P}_{\text {interaction }}=0.79$ for comparing with OSs; $\mathrm{P}_{\text {interaction }}=0.51$ for comparing with RCTs; major bleeding outcome: $\mathrm{P}_{\text {interaction }}=0.56$ for comparing with OSs; $\mathrm{P}_{\text {interaction }}=0.52$ for comparing with RCTs) or using adjusted effective size as the measurement (VTE outcome: $\mathrm{P}_{\text {interaction }}=0.74$ for comparing with OSs; major bleeding outcome: $\mathrm{P}_{\text {interaction }}=0.62$ for comparing with OSs) robust the primary results (Table S7).
Funnel plot was not performed as the limited number of included studies for OSs (10 studies) and RCTs (8 trials).

\section{Discussion}

To our best knowledge, present study is the first to evaluate the effectiveness and safety of DOACs versus conventional anticoagulants in CAT patients between OSs and RCTs. No significant difference in estimates for benefit outcome and safety outcome between OSs and RCTs was observed. Merged results from 10 OSs and 8 RCTs validated the reduced risk of VTE recurrence and comparable risk of major bleeding between patients receiving DOACs and conventional anticoagulants. Furthermore, it is worth noting that DOACs might associated with lowered risk of intracranial bleeding but increased risk of major GIB when compared to conventional anticoagulants.

Prior several systematic review and meta-analysis have assessed the benefits and harms of DOACs in patients with cancer, revealing that the use of DOACs conferred the similar risk of recurrent VTE and major bleeding when compared to conventional anticoagulants (9-15). However, these studies had limited value because of the inclusion of only minor proportion of cancer patients from phase III trials, therefore inevitably leading to the insufficient sample size estimation for the reduced risk of recurrent VTE from $3 \%$ to $5 \%$. In 2018, an updated meta-analysis of 8 RCTs, including latest Hokusai VTE Cancer trial, reported a significantly reduced risk of VTE recurrence in cancer patients with DOACs versus conventional anticoagulants, without increasing risk of major bleeding (42). While Li and colleagues recently reported an opposite result to previous meta-analysis (43). Another emerging RCTs (SELECT-D 

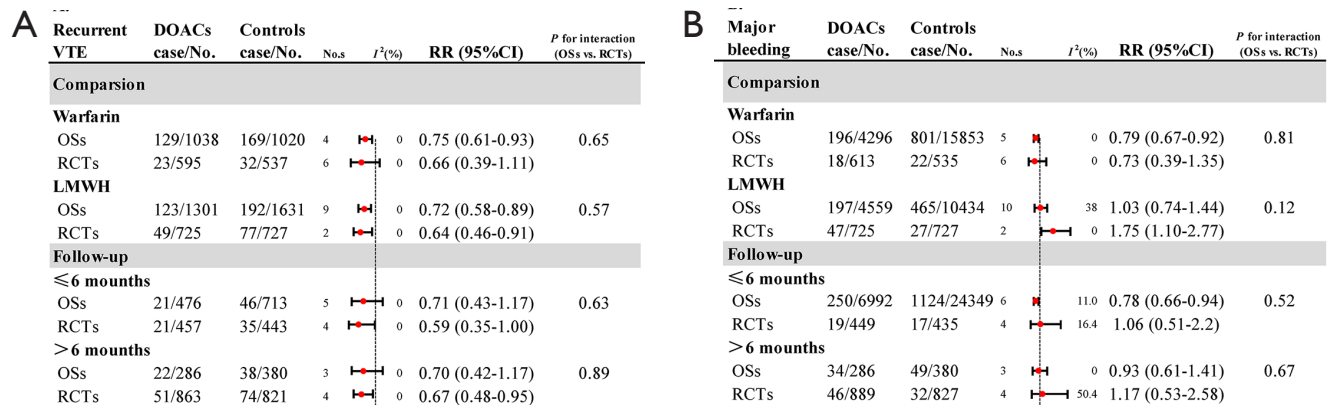

Figure 4 (A) Risk of recurrent VTE by comparison and follow-up and (B) risk of major bleeding by comparison and follow-up. LMWH, low molecular-weight heparins; RCTs, randomized controlled trials; OSs, observational studies; RR, relative risk; No., number of included studies.

trial) that directly compared rivaroxaban to dalteparin were also involved. The investigators emphasized that patients treated with DOACs were at lower risk of recurrent VTE but at higher risk of major bleeding than those assigned to LMWH (43). Given the above limitation and controversial results, it is necessary to reassess this issue by a rigorous method.

It is well-known that RCTs and their meta-analyses represent the highest quality of evidence. Whereas, the stringent inclusion and exclusion criteria of RCTs might lead to the enrollment of population with relatively low risk of VTE and bleeding when on anticoagulants, thus inevitably restricting the generalizability of results. On the contrary, OSs could enroll more representative patients than RCTs and provide more crucial evidence for the benefits and risks of an intervention, especially when there are gaps in evidence from RCTs (44). Thus, a comprehensive analysis of RCTs and OSs data would provide more robust evidence on drug efficacy and safety. In current study, we have collected all available evidences from 10 OSs and 8 RCTs to simultaneously evaluate the risk of recurrent VTE and major bleeding on DOACs, and perceived sources of heterogeneity were addressed by prior designed subgroup analyses. Patients characteristic and distribution of cancer types were comparable between OSs and RCTs. The pooled result from OSs was consistent with those from RCTs, thereby validating the reduced risk of recurrent VTE in CAT patients with DOACs versus conventional anticoagulants. Remarkably, the consistent results from OSs and RCTs conformed the conclusion of comparable risk of major bleeding between DOACs and conventional anticoagulants, which presented controversial in previous meta-analysis $(42,43)$.
As the serious medical condition, intracranial bleeding and GIB, has always been the main focus because they are the most frequent cause of major bleeding, mortality, as well as enormous burden on global health care utilization $(45,46)$. Current evidence has confirmed that DOACs use significantly reduced the risk of intracranial bleeding compared to warfarin in patients with atrial fibrillation (47). In present study, CAT patients treated with DOACs were also associated with decreased risk of intracranial bleeding, but at the expense of increase in the risk of major GIB. Given a variability of intracranial bleeding and GIB risk, screening for the risk of GIB should be considered before initiating anticoagulant therapy.

Regarding different comparators, patients receiving DOACs carried a decreased risk of recurrent VTE compared to those taking warfarin or LMWH. For major bleeding, our results from OSs documented that DOACs lowered the risk of major bleeding than warfarin, which might be explained by frequent interactions between warfarin and anticancer agents (including chemotherapeutic and immunosuppressive agents) and the poor control of time in therapeutic range (TTR) of warfarin in real world practice (48). By contrast, compared to LMWH, DOACs seems to be associated with a higher risk of major bleeding. The positive result was derived mainly from two latest RCTs that compared DOACs with dalteparin (Hokusai VTE Cancer and SELECT-D trial), which indicated that DOACs decreased the rate of recurrent VTE at the expense of more major GIB bleeding $(16,17)$. As the limited number of included studies, more RCTs and OSs are warranted to make definitive conclusions about the latter association.

To date, trials of head-to-head comparison between edoxaban/rivaroxaban and LMWH have been published. 
Due to the importance in field of CAT, growing trials related to other individual DOACs, including one for dabigatran (NCT03240120) and five for apixaban (NCT03692065, NCT02581176, NCT02366871, NCT02585713 and NCT03045406), are also actively underway. These ongoing RCTs will further our understanding of the optimal anticoagulation approach to management of VTE in cancer patients.

Several limitations should be addressed in our study. Firstly, among 8 RCTs, only two (Hokusai VTE Cancer and SELECT-D trials) were especially designed to assess VTE and bleeding risk of DOACs in patients with cancer. Therefore, the difference in the baseline characteristics in patients with DOACs and VKAs/LMWH could not be excluded. Secondly, unlike RCT, OS has a high risk of bias due to unmeasured confounders or inadequate control for measured confounders, and only two included OSs provided the adjusted data by using authorized method to minimize confounding. Thirdly, half of included OSs was not especially designed to assess the individual DOACs in patients with CAT. Fourthly, we have not got access to patient-level data in relation to the type, the stage or the location of cancer, making powerful subgroup analysis unavailable. Finally, we did not have the resources to review the non-English articles. However, we included studies identified in a comprehensive search of broad databases and are confident that this study covered the majority of studies in these special patients.

\section{Conclusions}

In summary, effectiveness and safety of DOACs versus conventional anticoagulants in CAT from OSs are in agreement with those from RCTs, confirming the reduced risk of recurrent VTE and similar risk of major bleeding between CAT patients receiving DOACs compared with those taking conventional anticoagulants. Furthermore, the use of DOACs might associated with lowered risk of intracranial bleeding but increased risk of major GIB. This discrepancy might be used to select oral anticoagulant regimen.

\section{Acknowledgments}

Funding: This study was funded by Research Funds of Shanghai Health and Family Planning commission (20184Y0022), Cultivation fund of clinical research of Renji hospital (PY2018-III-06), Clinical Pharmacy Innovation
Research Institute of Shanghai Jiao Tong University School of Medicine (CXYJY2019ZD001, CXYJY2019QN004), and Program for Key but Weak Disciplines of Shanghai Municipal Commission of Health and Family Planning (2016ZB0304).

\section{Footnote}

Conflicts of Interest: The authors have no conflicts of interest to declare.

Ethical Statement: The authors are accountable for all aspects of the work in ensuring that questions related to the accuracy or integrity of any part of the work are appropriately investigated and resolved.

\section{References}

1. Timp JF, Braekkan SK, Versteeg HH, et al. Epidemiology of cancer-associated venous thrombosis. Blood 2013;122:1712-23.

2. Khorana AA, Dalal MR, Lin J, et al. Health care costs associated with venous thromboembolism in selected highrisk ambulatory patients with solid tumors undergoing chemotherapy in the United States. Clinicoecon Outcomes Res 2013;5:101-8.

3. Mahajan A, Brunson A, White R, et al. The Epidemiology of Cancer-Associated Venous Thromboembolism: An Update. Semin Thromb Hemost 2019;45:321-5.

4. Khan AA, Lip GYH. Non-vitamin K antagonist oral anticoagulant dosing in patients with atrial fibrillation and renal dysfunction. Ann Transl Med 2017;5:465.

5. Lee AY, Levine MN, Baker RI, et al. Low-molecularweight heparin versus a coumarin for the prevention of recurrent venous thromboembolism in patients with cancer. N Engl J Med 2003;349:146-53.

6. Rawal A, Ardeshna D, Hesterberg K, et al. Is there an optimal "door to cath time" in the treatment of acute pulmonary embolism with catheter-directed thrombolysis? Ann Transl Med 2019;7:419.

7. Steffel J, Verhamme P, Potpara TS, et al. [The 2018 European Heart Rhythm Association Practical Guide on the use of non-vitamin $\mathrm{K}$ antagonist oral anticoagulants in patients with atrial fibrillation: executive summary]. Kardiol Pol 2018;76:1283-98.

8. Kearon C, Akl EA, Ornelas J, et al. Antithrombotic Therapy for VTE Disease: CHEST Guideline and Expert Panel Report. Chest 2016;149:315-52. 
9. van der Hulle T, den Exter PL, Kooiman J, et al. Meta-analysis of the efficacy and safety of new oral anticoagulants in patients with cancer-associated acute venous thromboembolism. J Thromb Haemost 2014;12:1116-20.

10. Carrier M, Cameron C, Delluc A, et al. Efficacy and safety of anticoagulant therapy for the treatment of acute cancerassociated thrombosis: a systematic review and metaanalysis. Thromb Res 2014;134:1214-9.

11. Larsen TB, Nielsen PB, Skjoth F, et al. Non-vitamin K antagonist oral anticoagulants and the treatment of venous thromboembolism in cancer patients: a semi systematic review and meta-analysis of safety and efficacy outcomes. PLoS One 2014;9:e114445.

12. Sardar P, Chatterjee S, Herzog E, et al. New oral anticoagulants in patients with cancer: current state of evidence. Am J Ther 2015;22:460-8.

13. Vedovati MC, Germini F, Agnelli G, et al. Direct oral anticoagulants in patients with VTE and cancer: a systematic review and meta-analysis. Chest 2015;147:475-83.

14. Brunetti ND, Gesuete E, De Gennaro L, et al. Direct oral anti-coagulants compared with vitamin-K inhibitors and low-molecular-weight-heparin for the prevention of venous thromboembolism in patients with cancer: A metaanalysis study. Int J Cardiol 2017;230:214-21.

15. Di Minno MND, Ageno W, Lupoli R, et al. Direct oral anticoagulants for the treatment of acute venous thromboembolism in patients with cancer: a meta-analysis of randomised controlled trials. 2017;50.

16. Raskob GE, van Es N, Verhamme P, et al. Edoxaban for the Treatment of Cancer-Associated Venous Thromboembolism. N Engl J Med 2018;378:615-24.

17. Young AM, Marshall A, Thirlwall J, et al. Comparison of an Oral Factor Xa Inhibitor With Low Molecular Weight Heparin in Patients With Cancer With Venous Thromboembolism: Results of a Randomized Trial (SELECT-D). J Clin Oncol 2018;36:2017-23.

18. Sherman RE, Anderson SA, Dal Pan GJ, et al. Real-World Evidence - What Is It and What Can It Tell Us? N Engl J Med 2016;375:2293-7.

19. Jarow JP, LaVange L, Woodcock J. Multidimensional Evidence Generation and FDA Regulatory Decision Making: Defining and Using "Real-World" Data. JAMA 2017;318:703-4.

20. Wei AH, Gu ZC, Zhang C, et al. Increased risk of myocardial infarction with dabigatran etexilate: fact or fiction? A critical meta-analysis of over 580,000 patients from integrating randomized controlled trials and realworld studies. Int J Cardiol 2018;267:1-7.

21. Liberati A, Altman DG, Tetzlaff J, et al. The PRISMA statement for reporting systematic reviews and meta-analyses of studies that evaluate health care interventions: explanation and elaboration. J Clin Epidemiol 2009;62:e1-34.

22. Schulman S, Angeras U, Bergqvist D, et al. Definition of major bleeding in clinical investigations of antihemostatic medicinal products in surgical patients. J Thromb Haemost 2010;8:202-4.

23. Higgins JP, Altman DG, Gotzsche PC, et al. The Cochrane Collaboration's tool for assessing risk of bias in randomised trials. BMJ 2011;343:d5928.

24. Romanelli RJ, Nolting L, Dolginsky M, et al. Dabigatran Versus Warfarin for Atrial Fibrillation in Real-World Clinical Practice: A Systematic Review and Meta-Analysis. Circ Cardiovasc Qual Outcomes 2016;9:126-34.

25. Higgins JP, Thompson SG, Deeks JJ, et al. Measuring inconsistency in meta-analyses. BMJ 2003;327:557-60.

26. Agnelli G, Buller HR, Cohen A, et al. Oral apixaban for the treatment of acute venous thromboembolism. $\mathrm{N}$ Engl J Med 2013;369:799-808.

27. Bauersachs R, Berkowitz SD, Brenner B, et al. Oral Rivaroxaban for Symptomatic Venous Thromboembolism. N Engl J Med 2010;363:2499-510.

28. Büller HR, Prins MH, Lensin AW, et al. Oral Rivaroxaban for the Treatment of Symptomatic Pulmonary Embolism. N Engl J Med 2012;366:1287-97.

29. Büller HR, Decousus H, Grosso MA, et al. Edoxaban versus warfarin for the treatment of symptomatic venous thromboembolism. N Engl J Med 2013;369:1406-15.

30. Schulman S, Kearon C, Kakkar AK, et al. Dabigatran versus Warfarin in the Treatment of Acute Venous Thromboembolism. N Engl J Med 2009;361:2342-52.

31. Schulman S, Kakkar AK, Goldhaber SZ, et al. Treatment of acute venous thromboembolism with dabigatran or warfarin and pooled analysis. Circulation 2014;129:764-72.

32. Alzghari SK, Seago SE, Garza JE, et al. Retrospective comparison of low molecular weight heparin vs. warfarin vs. oral Xa inhibitors for the prevention of recurrent venous thromboembolism in oncology patients: The ReCLOT study. J Oncol Pharm Pract 2018;24:494-500.

33. Chaudhury A, Balakrishnan A, Thai C, et al. The Efficacy and Safety of Rivaroxaban and Dalteparin in the Treatment of Cancer Associated Venous Thrombosis. Indian J Hematol Blood Transfus 2018;34:530-4.

34. Ross JA, Miller MM, Rojas Hernandez CM. Comparative effectiveness and safety of direct oral anticoagulants 
(DOACs) versus conventional anticoagulation for the treatment of cancer-related venous thromboembolism: A retrospective analysis. Thromb Res 2017;150:86-9.

35. Signorelli JR, Gandhi AS. Evaluation of rivaroxaban use in patients with gynecologic malignancies at an academic medical center: A pilot study. J Oncol Pharm Pract 2017. doi: 10.1177/1078155217739683.

36. Nicklaus MD, Ludwig SL, Kettle JK. Recurrence of malignancy-associated venous thromboembolism among patients treated with rivaroxaban compared to enoxaparin. J Oncol Pharm Pract 2018;24:185-9.

37. Phelps MK, Wiczer TE, Erdeljac HP, et al. A single center retrospective cohort study comparing low-molecularweight heparins to direct oral anticoagulants for the treatment of venous thromboembolism in patients with cancer - A real world experience. J Oncol Pharm Pract 2019;25:793-800.

38. Simmons B, Wysokinski W, Saadiq RA, et al. Efficacy and safety of rivaroxaban compared to enoxaparin in treatment of cancer associated venous thromboembolism. Eur J Haematol 2018. [Epub ahead of print].

39. Streiff MB, Milentijevic D. Effectiveness and safety of anticoagulants for the treatment of venous thromboembolism in patients with cancer. Am J Hematol 2018;93:664-71.

40. Zakai NA, Walker RF, MacLehose RF, et al. Impact of anticoagulant choice on hospitalized bleeding risk when treating cancer-associated venous thromboembolism. J Thromb Haemost 2018;16:2403-12.

41. Pritchard ER, Murillo JR, Jr., Putney D, et al. Singlecenter, retrospective evaluation of safety and efficacy of direct oral anticoagulants versus low-molecular-weight heparin and vitamin $\mathrm{K}$ antagonist in patients with cancer. J

Cite this article as: Gu ZC, Yan YD, Yang SY, Shen L, Kong LC, Zhang C, Wei AH, Li Z, Wang XH, Lin HW. Direct versus conventional anticoagulants for treatment of cancer associated thrombosis: a pooled and interaction analysis between observational studies and randomized clinical trials. Ann Transl Med 2020;8(4):95. doi: 10.21037/atm.2019.12.152
Oncol Pharm Pract 2019;25:52-9.

42. Al Yami MS, Badreldin HA, Mohammed AH, et al. Direct oral anticoagulants for the treatment of venous thromboembolism in patients with active malignancy: a systematic review and meta-analysis. J Thromb Thrombolysis 2018;46:145-53.

43. Li A, Garcia DA, Lyman GH, et al. Direct oral anticoagulant (DOAC) versus low-molecular-weight heparin (LMWH) for treatment of cancer associated thrombosis (CAT): A systematic review and meta-analysis. Thromb Res 2019;173:158-63.

44. Gu ZC, Wei AH, Zhang C, et al. Risk of Major Gastrointestinal Bleeding With New vs Conventional Oral Anticoagulants: A Systematic Review and Meta-analysis. Clin Gastroenterol Hepatol 2019. [Epub ahead of print].

45. Lanas A, Garcia-Rodriguez LA, Polo-Tomas M, et al. Time trends and impact of upper and lower gastrointestinal bleeding and perforation in clinical practice. Am J Gastroenterol 2009;104:1633-41.

46. Xu K, Chan NC. Bleeding in patients with atrial fibrillation treated with combined antiplatelet and anticoagulant therapy: time to turn the corner. Ann Transl Med 2019;7:S198.

47. Gu ZC, Zhou LY, Shen L, et al. Non-vitamin K Antagonist Oral Anticoagulants vs. Warfarin at Risk of Fractures: A Systematic Review and Meta-Analysis of Randomized Controlled Trials. Front Pharmacol 2018;9:348.

48. Yan YD, Zhang C, Shen L, et al. Net Clinical Benefit of Non-vitamin K Antagonist Oral Anticoagulants for Venous Thromboembolism Prophylaxis in Patients With Cancer: A Systematic Review and Trade-Off Analysis From 9 Randomized Controlled Trials. Front Pharmacol 2018;9:575. 
Table S1 Search strategy used in May 15, 2019

\begin{tabular}{|c|c|c|}
\hline Literature databases & Search items & Items found \\
\hline PUBMED & 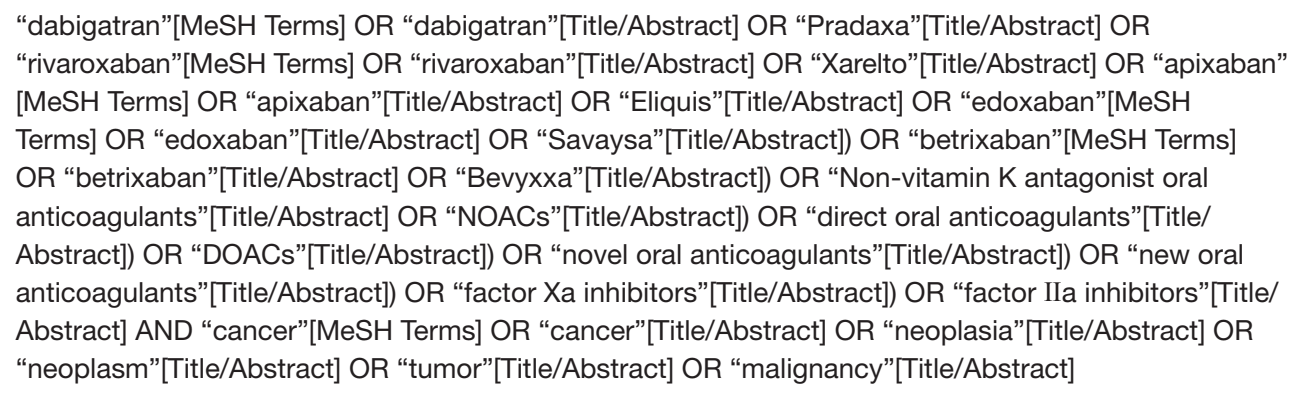 & 449 \\
\hline EMBASE & 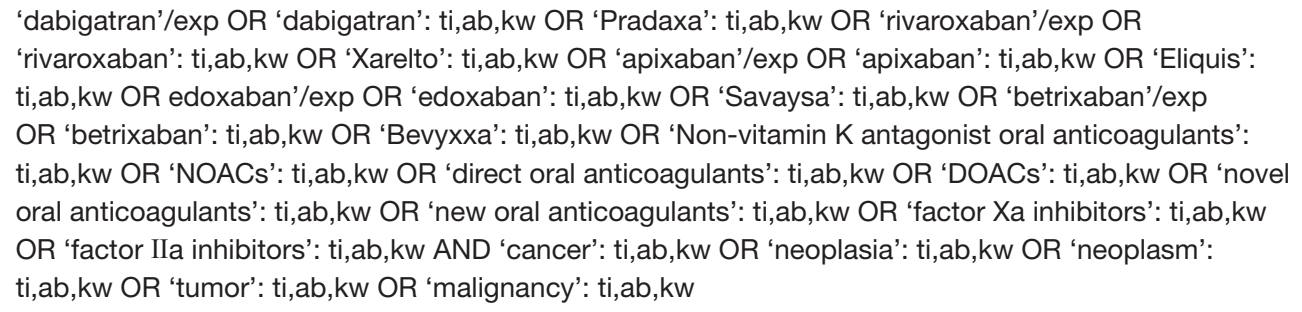 & 1,125 \\
\hline COCHRANE & $\begin{array}{l}\text { MeSH descriptor: [dabigatran] OR dabigatran: ti,ab,kw OR Pradaxa: ti,ab,kw OR MeSH descriptor: } \\
\text { [rivaroxaban] OR rivaroxaban: ti,ab,kw OR Xarelto: ti,ab,kw OR MeSH descriptor: [apixaban] OR } \\
\text { apixaban: ti,ab,kw OR Eliquis: ti,ab,kw OR MeSH descriptor: [edoxaban] OR edoxaban: ti,ab,kw OR } \\
\text { Savaysa: ti,ab,kw OR MeSH descriptor: [betrixaban] OR betrixaban: ti,ab,kw OR Bevyxxa: ti,ab,kw } \\
\text { OR Non-vitamin K antagonist oral anticoagulants: ti,ab,kw OR NOACs: ti,ab,kw OR direct oral } \\
\text { anticoagulants: ti,ab,kw OR DOACs: ti,ab,kw OR novel oral anticoagulants: ti,ab,kw OR new oral } \\
\text { anticoagulants: ti,ab,kw OR factor Xa inhibitors: ti,ab,kw OR factor IIa inhibitors: ti,ab,kw AND MeSH } \\
\text { descriptor: [cancer] OR cancer: ti,ab,kw OR neoplasia: ti,ab,kw OR neoplasm: ti,ab,kw OR tumor: } \\
\text { ti,ab,kw OR malignancy: ti,ab,kw }\end{array}$ & 180 \\
\hline Overall & & 1,754 \\
\hline Duplication & & 369 \\
\hline
\end{tabular}

Table S2 Excluded studies with reasons

\begin{tabular}{lll}
\hline Study & Drugs & Reason for exclusion \\
\hline Young 2018 (49) & Rivaroxaban & Overlapping period with Young 2018 (17) \\
Young 2018 (50) & Rivaroxaban & Overlapping period with Young 2018 (17) \\
Suwannoi 2018 (51) & DOACs & Conference abstract \\
Shimizu 2018 (52) & DOACs & Conference abstract \\
Schellong 2018 (53) & DOACs & Conference abstract \\
Raskob 2018 (54) & Edoxaban & Overlapping period with Raskob 2018 (16) \\
Rashid 2019 (55) & Dabigatran & Not for treatment in cancer and VTE \\
Ording 2018 (56) & DOACs & Conference abstract \\
Mulder 2018 (57) & Edoxaban & Overlapping period with Raskob 2018 (16) \\
Kraaijpoel 2018 (58) & Edoxaban & Overlapping period with Raskob 2018 (16) \\
Coleman 2018 (59) & Rivaroxaban & Conference abstract \\
Antonucci 2018 (60) & DOACs & Conference abstract \\
Angelini 2018 (61) & Rivaroxaban & Conference abstract \\
Shah 2018 (62) & DOACs & Not for treatment in cancer and VTE \\
Kim 2018 (63) & DOACs & Not for treatment in cancer and VTE \\
Chen 2019 (64) & Rivaroxaban & Not for treatment in cancer and VTE \\
\hline
\end{tabular}

DOAC, direct oral anticoagulants; VTE, venous thromboembolism. 
Table S3 Patient demographics and clinical characteristics of observational studies

\begin{tabular}{|c|c|c|c|c|c|c|c|c|c|c|c|c|c|c|c|c|c|c|c|c|c|c|c|c|}
\hline Study & $\begin{array}{l}\text { Total } \\
\text { number }\end{array}$ & $\begin{array}{l}\text { Mean } \\
\text { age }(y)\end{array}$ & $\begin{array}{l}\text { Female } \\
(\%)\end{array}$ & BMI $\left(\mathrm{kg} / \mathrm{m}^{2}\right)$ & HF $(\%)$ & HBP (\%) & DM $\%$ & ) Stroke/TIA (\%) & MI (\%) & $\begin{array}{l}\text { Renal } \\
\text { disease (\%) }\end{array}$ & $\begin{array}{l}\text { Liver } \\
\text { disease (\% }\end{array}$ & $\begin{array}{r}\text { Metastatic } \\
)^{\prime} \text { cancer }(\%)\end{array}$ & $\begin{array}{l}\text { Hematologic } \\
\text { cancer }(\%)\end{array}$ & $\begin{array}{l}\text { Gastric } \\
\text { cancer (\%) }\end{array}$ & $\begin{array}{l}\text { Pancreas } \\
\text { cancer }(\%)\end{array}$ & $\begin{array}{l}\text { Lung cancer } \\
(\%)\end{array}$ & $\begin{array}{l}\text { Lymphoma } \\
(\%)\end{array}$ & $\begin{array}{l}\text { Gynecologic } \\
\text { cancer }(\%)\end{array}$ & $\begin{array}{l}\text { Bladder } \\
\text { cancer (\%) }\end{array}$ & $\begin{array}{l}\text { Brain } \\
\text { cancer (\%) }\end{array}$ & $\begin{array}{l}\text { Prostate } \\
\text { cancer (\%) }\end{array}$ & $\begin{array}{l}\text { Breast } \\
\text { cancer }(\%)\end{array}$ & $\begin{array}{l}\text { Colorectal } \\
\text { cancer }(\%)\end{array}$ & $\begin{array}{l}\text { Genitourinary } \\
\text { cancer }(\%)\end{array}$ \\
\hline Alzghari 2018 (32) & 127 & 66.3 & 54 & NR & NR & NR & NR & NR & NR & NR & NR & 38 & NR & NR & $N R$ & 22 & NR & 13 & NR & NR & 10 & 14 & 14.2 & NR \\
\hline Chaudhury 2018 (33) & 286 & 60.4 & 48.7 & 28.8 & NR & 49 & 13.3 & NR & NR & NR & NR & 70 & 24.9 & NR & NR & $\mathrm{NR}$ & NR & NR & NR & NR & NR & NR & NR & NR \\
\hline Ross 2017 (34) & 153 & 59 & 56 & NR & NR & NR & $N R$ & NR & NR & NR & NR & 37.9 & 22.9 & $N R$ & NR & 4 & 16 & NR & NR & NR & NR & 22 & 5 & NR \\
\hline Signorelli 2017 (35) & 49 & 60 & NR & 30.6 & NR & NR & NR & NR & $\mathrm{NR}$ & NR & NR & 100 & NR & NR & NR & NR & NR & 100 & NR & NR & NR & NR & NR & NR \\
\hline Nicklaus 2018 (36) & 90 & $\mathrm{NR}$ & 57 & 29.4 & NR & NR & $\mathrm{NR}$ & NR & NR & NR & NR & 53 & 8 & NR & NR & $\mathrm{NR}$ & NR & NR & NR & NR & NR & NR & NR & NR \\
\hline Phelps 2019 (37) & 480 & 58 & 52 & 30 & NR & NR & NR & NR & NR & NR & NR & 53 & 24 & 21 & 5.8 & 13 & NR & 9 & NR & NR & NR & 9 & NR & NR \\
\hline Simmons 2018 (38) & 266 & 62.3 & 40.6 & 28.3 & $\mathrm{NR}$ & NR & NR & NR & NR & NR & NR & 55.6 & 10.9 & 20 & 10.9 & 8.3 & NR & NR & $\mathrm{NR}$ & 3 & 4.1 & 6.4 & $\mathrm{NR}$ & 9.4 \\
\hline Streiff 2018 (39) & 1,367 & 72.7 & 51.6 & NR & 15 & 72.2 & 33.1 & 4.8 & NR & 16.1 & 17.4 & NR & NR & 2.1 & 5.4 & 17.8 & 5.2 & 6.2 & 3.9 & 3.5 & NR & NR & NR & NR \\
\hline Zakai 2018 (40) & 26,826 & 63.2 & 51.5 & NR & 14.8 & 63.7 & 26.2 & 16.5 & 7 & 12.5 & 20.5 & NR & 13.2 & NR & $N R$ & 14.6 & NR & NR & NR & NR & 9.5 & 14.5 & 9.6 & NR \\
\hline Pritchard 2019 (41) & 258 & 66.7 & 56.7 & 27.3 & NR & NR & NR & NR & NR & NR & NR & 50.3 & 24.3 & 11.7 & NR & 15.3 & NR & NR & NR & NR & & 20.7 & NR & \\
\hline
\end{tabular}

BMI: Body Mass Index; HF: Heart failure; HBP: Hypertension; DM: Diabetes; TAA: transient ischemic attack; Ml: myocardial infarction; NR: not reported

Table S4 Patient demographics and clinical characteristics of RCTs

\begin{tabular}{|c|c|c|c|c|c|c|c|c|c|c|c|c|c|c|c|c|c|c|c|}
\hline Study & $\begin{array}{l}\text { Total } \\
\text { number }\end{array}$ & Mean age $(y)$ & ) Female (\%) & Weight $(\mathrm{kg})$ & BMI $\left(\mathrm{kg} / \mathrm{m}^{2}\right)$ & $\operatorname{Cor}(\mathrm{m} L / \mathrm{m}$ & in) Metastatic & $\begin{array}{l}\text { Hematologic } \\
(\%)\end{array}$ & Gastric cancer (\%) & $\begin{array}{l}\text { Pancreas } \\
\text { cancer (\%) }\end{array}$ & Lung cancer $(\%)$ & Lymphoma (\%) & $\begin{array}{l}\text { Gynecologic } \\
\text { cancer }(\%)\end{array}$ & Bladder cancer (\%) & Brain cancer (\%) & $\begin{array}{l}\text { Prostate } \\
\text { cancer (\%) }\end{array}$ & Breast cancer (\%) & $\begin{array}{l}\text { Colorectal } \\
\text { cancer }(\%)\end{array}$ & $\begin{array}{l}\text { Genitourinary } \\
\text { cancer }(\%)\end{array}$ \\
\hline SELECT-D (17) & 406 & 67 & 47 & NR & 26.7 & NR & 58 & 2.5 & 2.5 & 7 & 11.5 & 5.5 & 3 & 3.5 & 1 & NR & 10 & 25 & NR \\
\hline Hokusai VTE Cancer (16 & 5) 1,046 & 64 & 47.7 & 79 & NR & NR & 53 & 10.6 & NR & NR & 14.6 & NR & 10.5 & NR & NR & NR & 11.9 & 15.5 & 13 \\
\hline AMPLIFY (26) & 169 & 65.3 & 41.4 & 80.4 & NR & NR & NR & NR & NR & NR & NR & NR & NR & NR & NR & NR & NR & NR & NR \\
\hline $\begin{array}{l}\text { EINSTEIN- PE/DVT } \\
(27,28)\end{array}$ & 462 & NR & 43.5 & NR & 27.1 & NR & 22 & 14.5 & 14.3 & NR & 7.4 & NR & NR & NR & 1.5 & NR & 11.5 & NR & 31 \\
\hline Hokusai-VTE (29) & 208 & 65.5 & 44.5 & NR & NR & NR & NR & NR & 2 & 1 & 6 & 4 & NR & 4 & 1.5 & 12 & 16.5 & NR & NR \\
\hline RECOVER- I/II $(30,31)$ & 221 & 64.4 & 53 & 77.1 & 27.2 & 85.7 & 12.7 & 12.2 & 1.8 & 0.5 & 7.7 & NR & 12.2 & 4.5 & 1.4 & 20.4 & 13.6 & 14 & NR \\
\hline
\end{tabular}

$\mathrm{RCT}$, randomized controlled trial; BMI, body mass index; CCr, creatinine clearance rate; $\mathrm{NR}$, not reported 
Table S5 Sensitivity analysis of OSs and RCTs in recurrent VTE

\begin{tabular}{ll}
\hline Omitted studies & RR $(95 \% \mathrm{Cl})$ \\
\hline OSs & $0.74(0.64-0.86)$ \\
Alzghari 2018 & $0.74(0.64-0.86)$ \\
Chaudhury 2018 & $0.74(0.63-0.86)$ \\
Ross 2017 & $0.74(0.63-0.86)$ \\
Signorelli 2017 & $0.74(0.63-0.86)$ \\
Nicklaus 2018 & $0.73(0.63-0.85)$ \\
Phelps 2019 & $0.74(0.64-0.86)$ \\
Simmons 2018 & $0.73(0.60-0.90)$ \\
Streiff 2018 & $0.73(0.63-0.85)$ \\
Pritchard 2019 & \\
RCTs & $0.68(0.50-0.93)$ \\
SELECT-D & $0.59(0.38-0.91)$ \\
Hokusai-Cancer & $0.65(0.49-0.87)$ \\
AMPLIFY & $0.65(0.48-0.87)$ \\
EINSTEIN-PE/DVT & $0.66(0.49-0.88)$ \\
Hokusai-VTE & $0.63(0.46-0.86)$ \\
RECOVER-I/II &
\end{tabular}

RCTs, randomized controlled trials; OSs, observational studies; VTE, venous thromboembolism; $R R$, relative risk.

Table S6 Sensitivity analysis of OSs and RCTs in major bleeding

\begin{tabular}{ll}
\hline Omitted studies & RR $(95 \% \mathrm{Cl})$ \\
\hline OSs & $0.91(0.75-1.09)$ \\
Alzghari 2018 & $0.89(0.75-1.06)$ \\
Chaudhury 2018 & $0.90(0.75-1.07)$ \\
Ross 2017 & $0.91(0.75-1.09)$ \\
Signorelli 2017 & $0.91(0.76-1.09)$ \\
Nicklaus 2018 & $0.90(0.78-1.05)$ \\
Phelps 2019 & $0.89(0.75-1.07)$ \\
Simmons 2018 & $0.90(0.73-1.11)$ \\
Streiff 2018 & $0.96(0.80-1.11)$ \\
Zakai 2018 & \\
RCTs & $1.02(0.57-1.82)$ \\
SELECT-D & $0.94(0.55-1.64)$ \\
Hokusai-Cancer & $1.27(0.79-2.03)$ \\
AMPLIFY & $1.45(0.97-2.14)$ \\
EINSTEIN-PE/DVT & $1.09(0.62-1.91)$ \\
Hokusai-VTE & $1.21(0.70-2.12)$ \\
RECOVER-I/II & \\
RCTs, randomizedcontroled & \\
\hline
\end{tabular}

RCTs, randomized controlled trials; OSs, observational studies; VTE, venous thromboembolism; $R R$, relative risk.
Table S7 Sensitivity analysis by pooling OSs and RCTs, and using adjusted effective size as the measurement

\begin{tabular}{lll}
\hline Items & RR $(95 \% \mathrm{Cl})$ & P for interaction \\
\hline Pooling OSs and RCTs & & \\
VTE in OSs and RCTs & $0.72(0.63-0.82)$ & Reference \\
VTE in OSs & $0.65(0.49-0.86)$ & 0.79 \\
VTE RCTs & $0.74(0.63-0.86)$ & 0.51 \\
MB in OSs and RCTs & $0.97(0.81-1.16)$ & Reference \\
MB in OSs & $1.17(0.72-1.88)$ & 0.56 \\
MB in RCTs & $0.90(0.76-1.07)$ & 0.52 \\
Using adjusted effective size & \\
VTE in OSs (adjusted & $0.71(0.58-0.84)$ & Reference \\
data) & & \\
VTE in OSs & $0.74(0.63-0.86)$ & 0.74 \\
VTE in OSs (adjusted & $0.85(0.72-0.97)$ & Reference \\
data) & & \\
VTE in OSs & $0.90(0.76-1.07)$ & 0.62 \\
\hline
\end{tabular}

RCTs, randomized controlled trials; OSs, observational studies; $\mathrm{RR}$, relative risk; VTE, venous thromboembolism; $\mathrm{MB}$, major bleeding. 


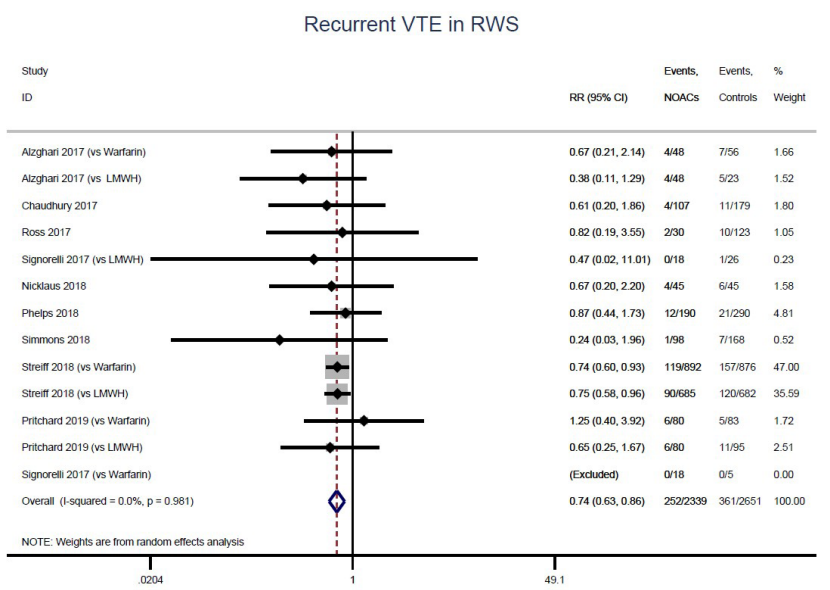

Figure S1 Recurrent VTE of OSs. VTE, venous thromboembolism; OSs, observational studies.

Recurrent VTE in RCT

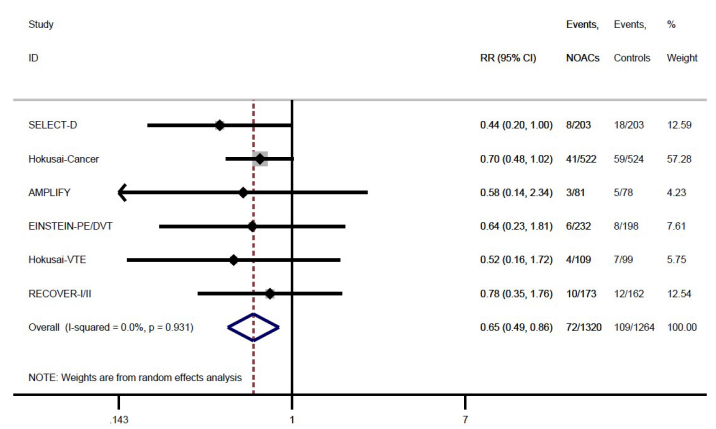

Figure S2 Recurrent VTE of RCTs. VTE, venous thromboembolism; RCTs, randomized controlled trials.

Recurrent VTE by drugs (RWSs)

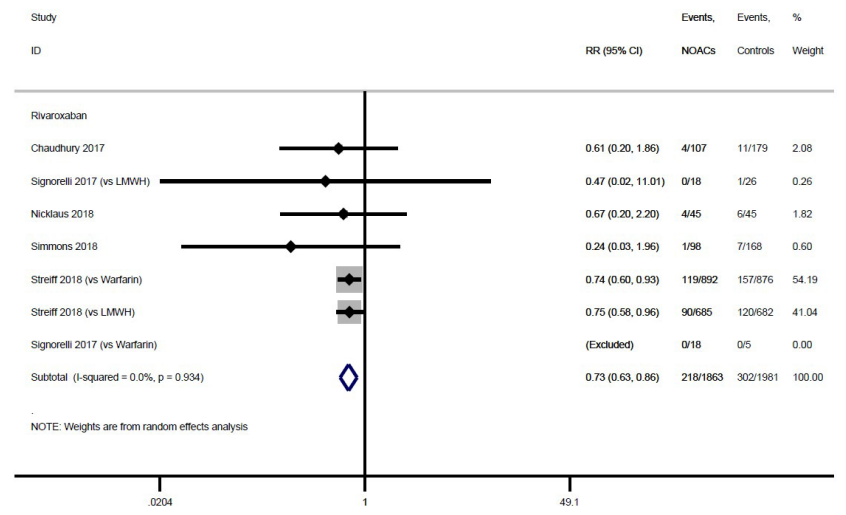

Figure S3 Recurrent VTE by drugs (OSs). VTE, venous thromboembolism; OSs, observational studies.

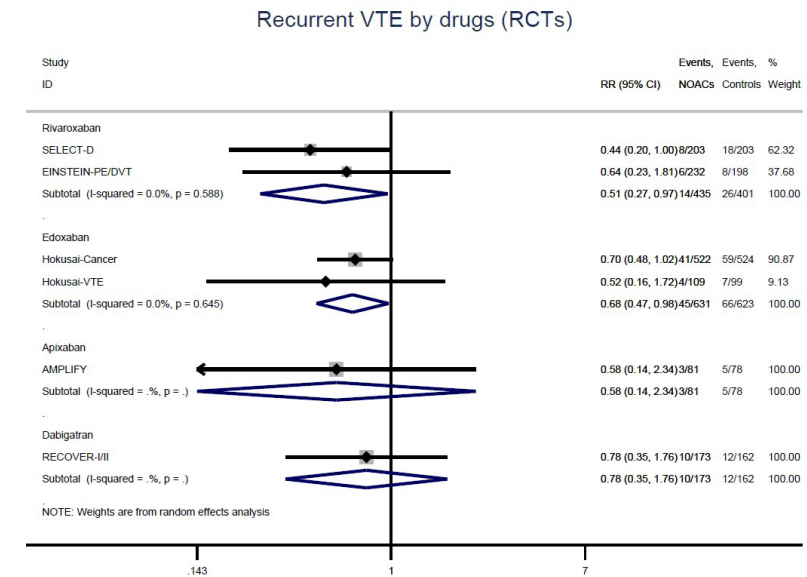

Figure S4 Recurrent VTE by drugs (RCTs). VTE, venous thromboembolism; RCTs, randomized controlled trials.

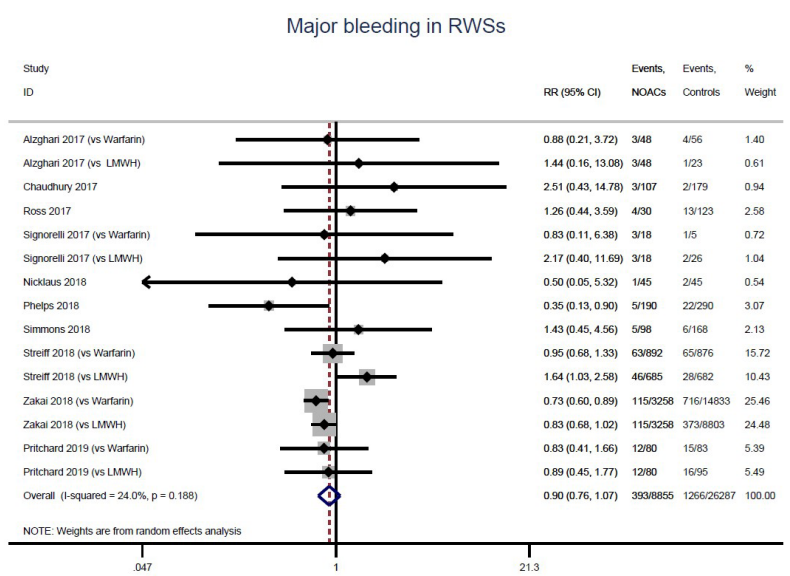

Figure S5 Major bleeding of OSs. OSs, observational studies.

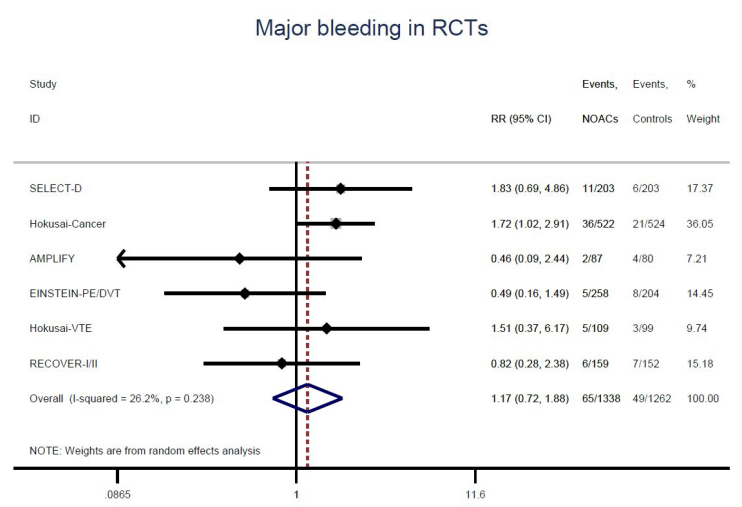

Figure S6 Major bleeding of RCTs. RCTs, randomized controlled trials. 
Major bleeding by drugs (RWSs)

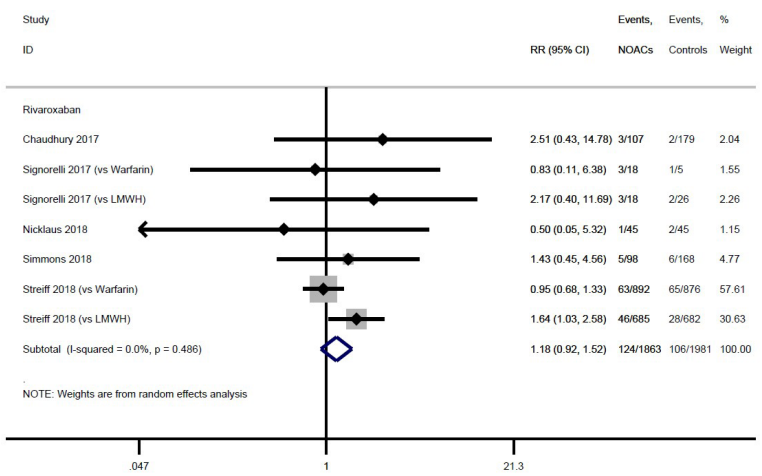

Figure S7 Major bleeding by drugs (OSs). OSs, observational studies.

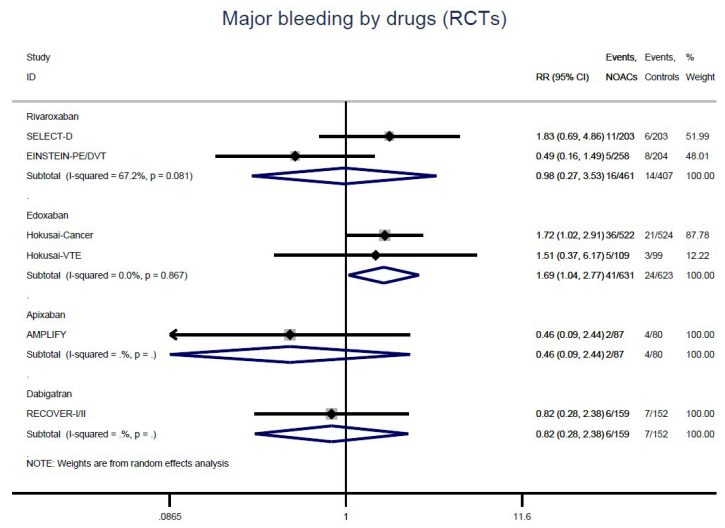

Figure S8 Major bleeding by drugs (RCTs). RCTs, randomized controlled trials.

CRNMB in RWSs

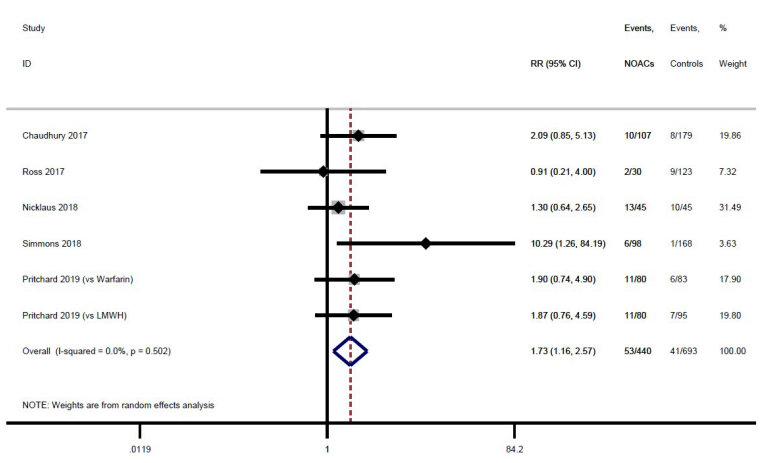

Figure S9 Clinical relative non-major bleeding of OSs. OSs, observational
CRNMB in RCTs

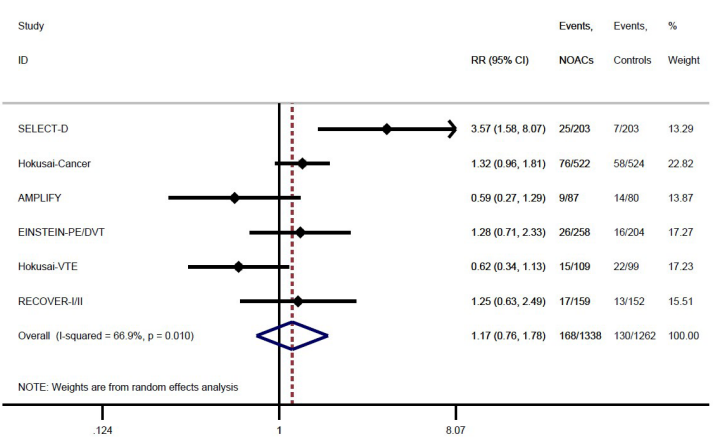

Figure S10 Clinical relative non-major bleeding of RCTs. RCTs, randomized controlled trials.

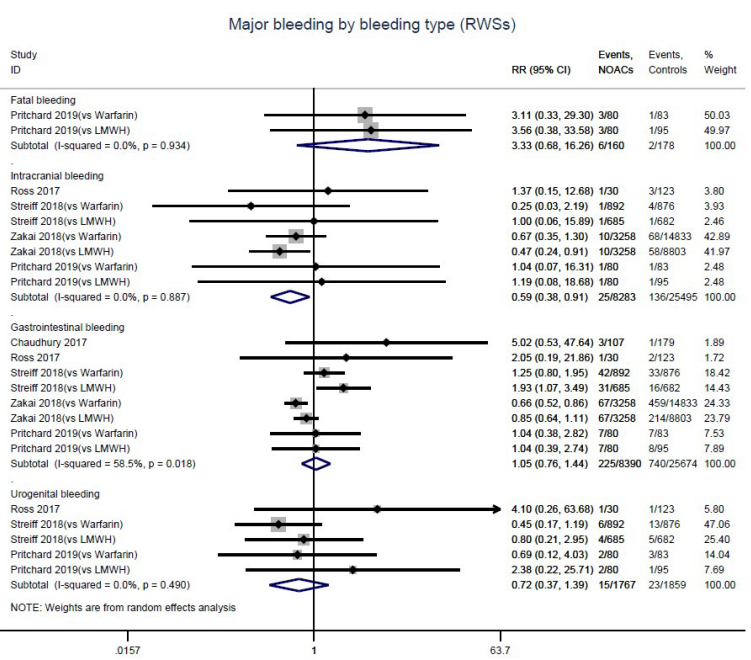

Figure S11 Major bleeding by bleeding type (OSs). OSs, observational studies.

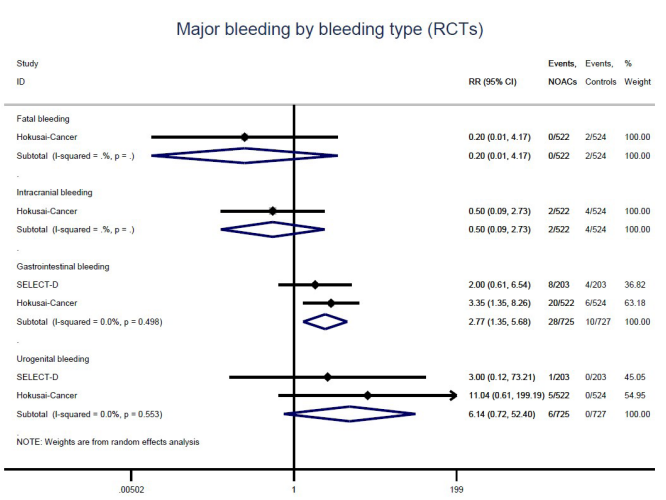

Figure S12 Major bleeding by bleeding type (RCTs). RCTs, randomized controlled trials. 


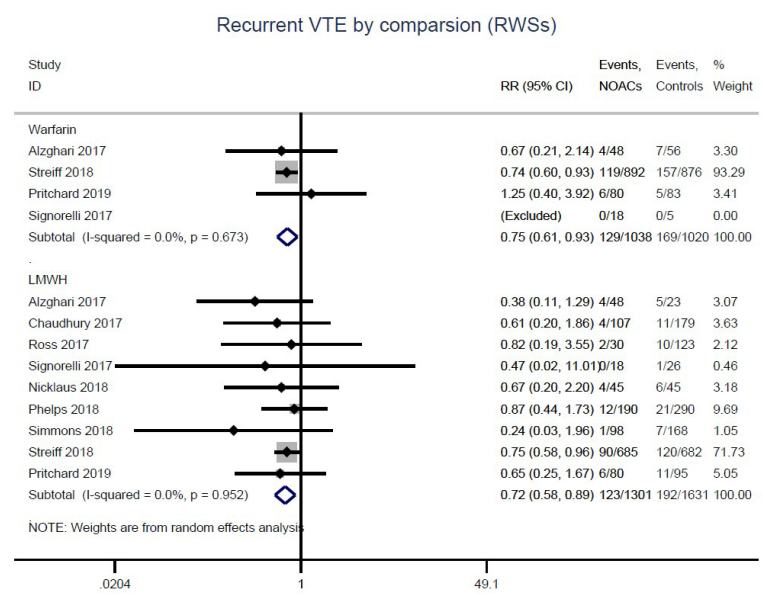

Figure S13 Recurrent VTE by comparison (OSs). VTE, venous thromboembolism; OSs, observational studies.

Recurrent VTE by comparsion (RCTs)

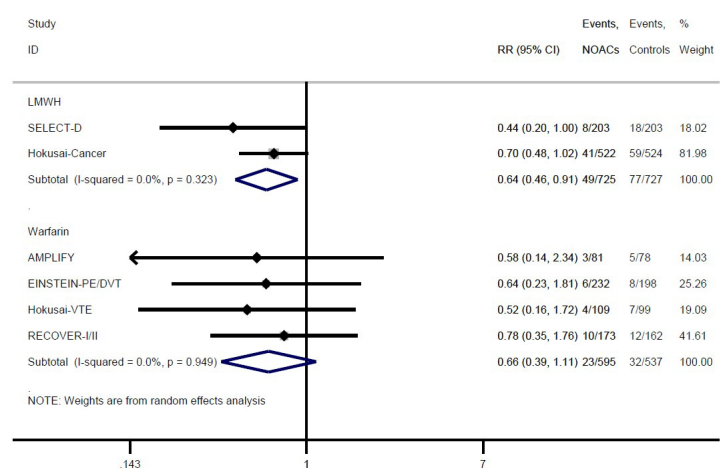

Figure S14 Recurrent VTE by comparison (RCTs). VTE, venous thromboembolism; RCTs, randomized controlled trials.

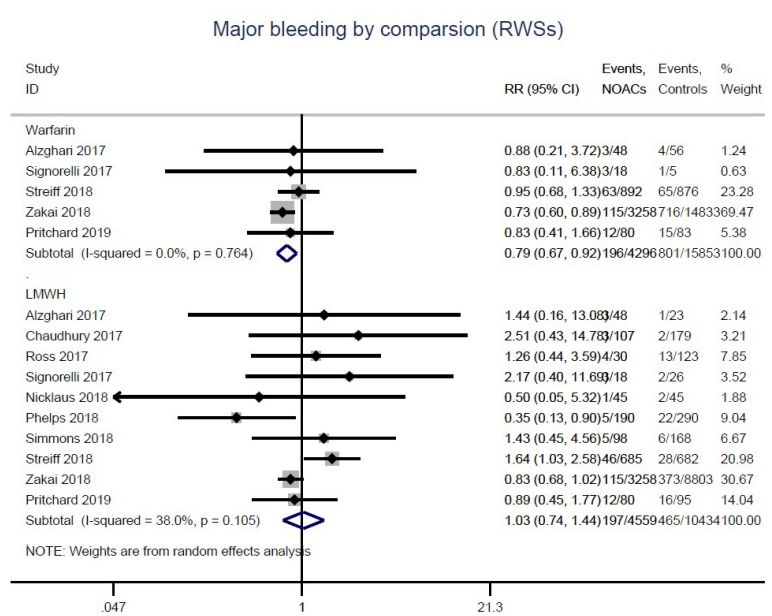

Figure S15 Major bleeding by comparison (OSs). OSs, observational studies.

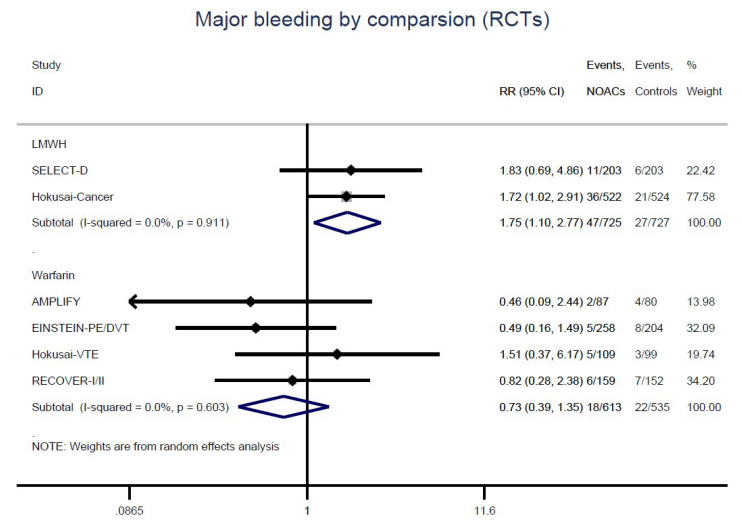

Figure S16 Major bleeding by comparison (RCTs). RCTs, randomized controlled trials.

Recurrent VTE by follow-up (RWSs)

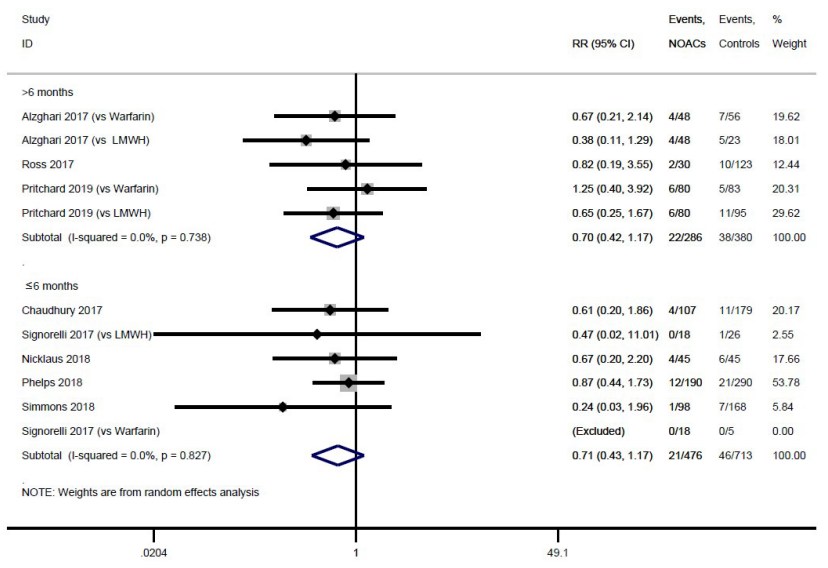

Figure S17 Recurrent VTE by follow-up (OSs). VTE, venous thromboembolism; OSs, observational studies.

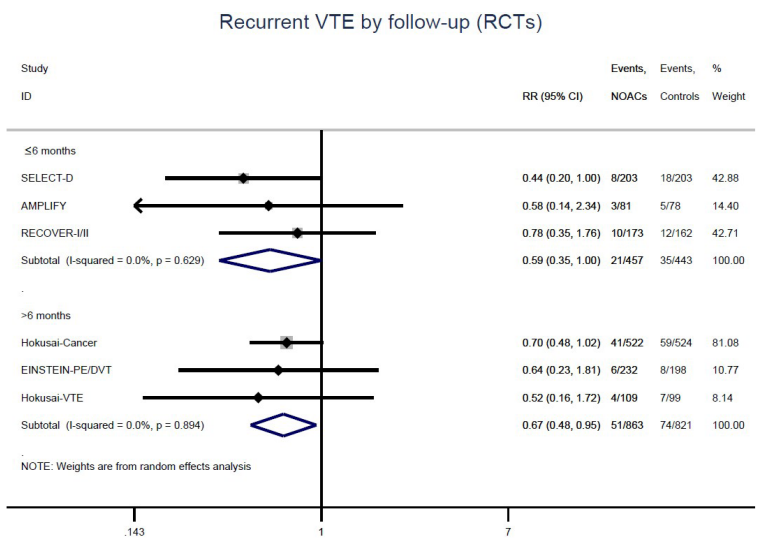

Figure S18 Recurrent VTE by follow-up (RCTs). VTE, venous thromboembolism; RCTs, randomized controlled trials. 


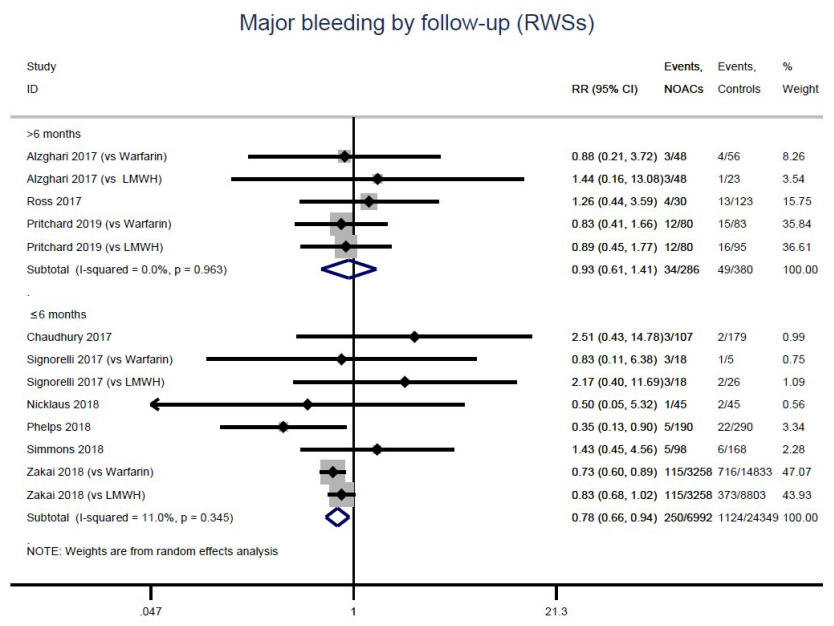

Figure S19 Major bleeding by comparison (OSs). OSs, observational studies.

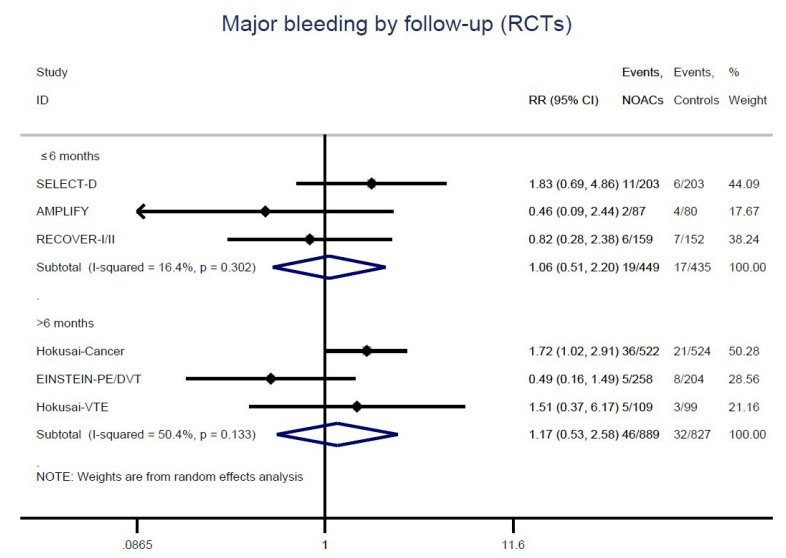

Figure S20 Major bleeding by follow-up (RCTs). RCTs, randomized controlled trials.

\section{References}

49. Young A, Marshall A, Thirwall J, et al. Oral option for the treatment of venous thromboembolism in cancer patients? Support Care Cancer 2018;26:S338.

50. Young A, Marshall A, Thirlwall J, et al. Anticoagulation therapy in SELECTeD cancer patients at risk of recurrence of venous thromboembolism: Results of the 'select-d' pilot trial. Thromb Res 2018;164:S194.

51. Suwannoi L, Chumnumwat S, Konmun J, et al. Retrospective evaluation in efficacy and safety of direct oral anticoagulants for treatment of venous thromboembolism in cancer patients in Thailand. Support Care Cancer 2018;26:S333.

52. Shimizu A, Sawada K, SHiomi M, et al. Direct oral anticoagulants are effective and safe in patients with gynecologic cancer. Int J Gynecol Cancer 2018;28:564.

53. Schellong S, Heinken A, Kretzschmar A, et al.

Anticoagulation in patients with cancer and thrombosisPatterns of medical care according to routine data from the German statutory health insurance [CERTIFICAT]. Vasa - European Journal of Vascular Medicine 2018;47:31.

54. Raskob G, Van Es N, Verhamme P, et al. Edoxaban versus dalteparin for treatment of venous thromboembolism (VTE) associated with cancer: Hokusai V'TE-cancer randomized trial. Support Care Cancer 2018;26:S316-7.

55. Rashid MF, Jackson TL, Morgan JA, et al. Dabigatran (Pradaxa) Is Safe for Extended Venous Thromboembolism Prophylaxis After Surgery for Pancreatic Cancer. J Gastrointest Surg 2019;23:1166-71.

56. Ording AG, Veres K, Adelborg K, et al. 30-day mortality in cancer patients with atrial fibrillation and bleeding following treatment with warfarin or non-Vitamin $\mathrm{K}$ oral antagonists. Thromb Res 2018;164:S220.

57. Mulder FI, van Es N, Kraaijpoel N, et al. Efficacy and safety of edoxaban in clinically relevant subgroups: Results from the Hokusai VTE Cancer randomized trial. Thromb Res 2018;164:S194.

58. Kraaijpoel N, Di Nisio M, Mulder FI, et al. Clinical Impact of Bleeding in Cancer-Associated Venous Thromboembolism: Results from the Hokusai VTE Cancer Study. Thromb Haemost 2018;118:1439-49.

59. Coleman CI, Bunz TJ, Kohn CG, et al. Effectiveness and safety of rivaroxaban versus warfarin for treatment of cancer-associated venous thrombosis. Thromb Res 2018;164:S203

60. Antonucci E, Falanga A, Barcella L, et al. Cancerassociated venous thromboembolism: Results from the prospective multicenter START2-registry study. Blood Transfusion 2018;16:S512.

61. Angelini DE, Rahman S, Poudel S, et al. Treatment outcomes of cancer associated venous thrombosis; The cleveland clinic experience. Thromb Res 2018;164:S205-6.

62. Shah S, Norby FL, Datta YH, et al. Comparative effectiveness of direct oral anticoagulants and warfarin in patients with cancer and atrial fibrillation. Blood Adv 2018;2:200-9.

63. Kim K, Lee YJ, Kim TH, et al. Effect of non-Vitamin $\mathrm{K}$ antagonist oral anticoagulants in atrial fibrillation patients with newly diagnosed cancer. Korean Circ J 2018;48:406-17.

64. Chen ST, Hellkamp AS, Becker RC, et al. Efficacy and Safety of Rivaroxaban versus Warfarin in Patients with Nonvalvular Atrial Fibrillation and a History of Cancer: Observations from ROCKET AF. Eur Heart J Qual Care Clin Outcomes 2019;5:145-52. 